\title{
Economía política y pugnas por la hegemonía. Disputas en torno al núcleo nodal de la hegemonía neoliberal y los proyectos de devaluación y dolarización durante la crisis del 2001
}

\author{
Political economy and struggles for hegemony. Disputes around the nodal nucleus of neoliberal hegemony and the \\ projects of devaluation and dollarization during the crisis of 2001
}

Hernán Fair

CONICET-Universidad Nacional de Quilmes, Argentina

hernanfair@conicet.gov.ar

\section{RESUMEN:}

Este artículo analiza los discursos en pugna de los principales actores de poder en torno al núcleo nodal de la hegemonía neoliberal en la Argentina, a través de los posicionamientos y disputas público-mediáticas sobre los significantes clave Convertibilidad y estabilidad y los proyectos de devaluación y dolarización, durante la crisis de diciembre del 2001. Se encontró que una parte minoritaria de los actores políticos clave apoyaban, con matices, los fundamentos del orden neoliberal, que en esta fase se articulaban de forma extensiva a la preservación del sistema financiero y los ahorros, la gobernabilidad y la estabilidad institucional. Al mismo tiempo, una pluralidad de actores políticos criticaban, con diferentes intensidades, la Convertibilidad, sus efectos regresivos y las interpelaciones oficiales, aunque mantenían un apoyo tácito a la estabilidad. En este tramo final de la crisis del modelo la propuesta de dolarización era readecuada a partir de un proyecto financiero-neoliberal de fluctuación ponderada del tipo de cambio y posterior dolarización de la economía. Esta opción implicaba extremar el esquema convertible y el ajuste fiscal. Sin embargo, el proyecto dolarizador era impugnado por el conjunto de los referentes heterodoxos y rechazado también por el presidente. $\mathrm{Al}$ analizar los discursos alternativos en torno a la devaluación se encontró que, salvo unas pocas voces aisladas, los actores predominantes no mencionaban, o bien rechazaban explícitamente, esta propuesta, que simbolizaba la pura anti-comunidad. A su vez, un conjunto de actores de poder enunciaban los significantes devaluación y dolarización, a lo que se sumaba el peligro del default, aunque sin respaldar dichos proyectos. Estos referentes se limitaban a constatar la situación de crisis y a proyectar, con diferentes grados de pesimismo, una salida devaluacionista, dolarizadora y/o de cesación de pagos de la deuda, pero sin apoyar ninguna de estas alternativas. Por último, en esta fase se escenificaba una variante heterodoxa radicalizada de devaluación encubierta. Dicha propuesta consistía en una flexibilización con flotación cambiaria y desdolarización para construir un modelo de país alternativo, vinculado a la redistribución del ingreso, la protección del trabajo y el mercado interno y el desarrollo productivo nacional. Sin embargo, este proyecto antagónico al orden neoliberal representaba a posiciones minoritarias, aisladas y desarticuladas a nivel político-institucional y social. De este modo, no contaba con los consensos necesarios ni la fuerza performativa para estructurar un nuevo modelo de desarrollo. Se concluye que la desarticulación hegemónica, y el veto mutuo entre los actores de poder, obturaron la posibilidad de viabilizar un programa alternativo al Régimen de Convertibilidad.

Palabras Clave: Disputas por la hegemonía, Análisis del Discurso, Modelo de Convertibilidad, Proyectos de Devaluación/ Dolarización, Política y Economía.

\begin{abstract}
:
This article analyzes the discourses of the main power actors around the nodal nucleus of neoliberal hegemony in Argentina, through the public-mediatic positions and disputes about the key signifiers Convertibility and Stability and the devaluation and dollarization projects, during the crisis of December 2001. It found that a minority of the key political actors supported, with nuances, the basics of the neoliberal order, which in this phase were articulated extensively to the preservation of the financial system and savings, governability and institutional stability. At the same time, a plurality of political actors criticized, with different intensities, Convertibility, its regressive effects and official interpellations, although they maintained a tacit support to stability. In this final stretch of the crisis, the option of dollarization was readapted from a financial-neoliberal project of weighted fluctuation of the exchange rate and subsequent dollarization of the economy. This involved extreme the convertible scheme and the fiscal adjustment. However, the dollarization project was contested by heterodox referents and rejected also by the President. When analyzing the alternative discourses around devaluation, it found that, except for a few isolated voices, the predominant actors did not mention or explicitly rejected this proposal, which symbolized anti-community. In turn, a set of power actors enunciated the devaluation and dollarization signifiers, which was added the danger of default, although without endorsing such projects. These referents were limited to verify the crisis situation and to project, with different degrees of pessimism, a devaluation, dollarization
\end{abstract}


and/or debt cessation of payments, but without supporting any of these alternatives. Finally, in this phase it staged a radicalized heterodox variant of covert devaluation. This proposal consisted in a flexibilization and exchange flotation with de-dollarization to build an alternative country model that redistributes income, protects labor and the domestic market and promotes national productive development. However, these projects antagonistic to the neoliberal order constituted minority positions, isolated and disjointed at political-institutional and social level. In this way, they did not have the necessary consensus either the performative force to articulate another development model. It is concluded that the hegemonic disarticulation and the mutual vetoes between the power actors obturated the possibility of making feasible an alternative program to the Convertibility Regime.

KEYWORDS: Disputes over hegemony, Discourse Analysis, Convertibility Model, Projects of Devaluation, Dollarization, Politics and Economy.

\section{INTRODUCCIÓN}

El presente trabajo, inscripto en el marco de una investigación más amplia sobre los posicionamientos y disputas de sentido durante la crisis de la hegemonía neoliberal en la Argentina del 2001, se propone como objetivo general analizar los discursos en pugna de los actores políticos clave (presidente, ministros de Gobierno, dirigentes de las principales fuerzas político-partidarias, economistas, empresarios, sindicalistas, periodistas y editorialistas de los grandes medios, banqueros y operadores financieros, acreedores externos y otros referentes de poder del establishment internacional) en torno a los fundamentos del modelo económico y social, durante la fase de crisis terminal del modelo de Convertibilidad. Los objetivos particulares consisten en (1) Examinar los posicionamientos y disputas públicas del presidente, sus ministros, los empresarios, los economistas, los periodistas de la prensa escrita y el resto de los actores políticos clave en torno al núcleo nodal de la hegemonía neoliberal durante la crisis de diciembre del 2001, a través del análisis de los significantes clave Convertibilidad y estabilidad; y (2) Analizar los posicionamientos y disputas hegemónicas de los principales actores de poder en torno a los proyectos de devaluación y dolarización de la economía y sus significados adosados, en la misma etapa. Se busca responder a los siguientes interrogantes. En primer lugar, ¿cómo se posicionaban el presidente, sus principales ministros y el resto de los actores políticos clave frente a los fundamentos del orden neoliberal? En este sentido, ¿existían durante la crisis de diciembre de 2001 posiciones críticas de la Convertibilidad y de la estabilidad económica? En segundo término, ¿en qué medida se presentaban en esta fase reclamos prodevaluacionistas y dolarizadores, quiénes eran los principales exponentes que enarbolaban estos discursos y qué significados construían para legitimar dichos proyectos políticos? Finalmente, ¿̨por qué, en un contexto de virtual desintegración del orden capitalista-neoliberal, los referentes más críticos del neoliberalismo no pudieron organizar y viabilizar un programa alternativo al Régimen de Convertibilidad?

Numerosos estudios analizaron el período de crisis del modelo de Convertibilidad, reformas y ajustes neoliberales en la Argentina (1998-2001) desde el campo de la economía política, la sociología política, la sociología económica, la administración y políticas públicas y la historia reciente. Sin embargo, hasta el momento no se investigó, desde una metodología de Análisis Político del Discurso (APD), las vinculaciones entre la crisis del orden neoliberal, las luchas hegemónicas y los posicionamientos políticos. De manera específica, carecemos de un análisis íntegramente discursivo de los posicionamientos y disputas por la hegemonía que incluya al presidente, sus ministros y a los principales actores de poder del sistema político (economistas, empresarios, periodistas y editorialistas de los medios masivos de comunicación, sindicalistas, dirigentes de las fuerzas político-partidarias, banqueros y operadores financieros, acreedores externos y otros referentes del establishment internacional), tanto en términos individuales como organizados de forma colectiva, en torno a los significantes clave estabilidad y Convertibilidad. Tampoco contamos con investigaciones en ciencia política que, partiendo desde la teoría posgramsciana de la hegemonía, se enfoquen en el análisis discursivo de los proyectos de devaluación, dolarización y sus significados adosados, durante la crisis de diciembre del 2001. El siguiente trabajo se propone aportar al desarrollo de la investigación social empírica en esta línea. 


\section{Perspectiva teórica y estrategia metodológica}

La presente investigación toma como eje herramientas de la teoría de la hegemonía de Laclau. Esta perspectiva, también conocida como Teoría del Discurso de Essex, parte de la base de la construcción discursiva de la realidad social, postula el carácter constitutivo de los antagonismos y la contingencia radical de lo social y asume una visión ampliada del discurso, que articula a los elementos lingísticos y no meramente lingísticos en una misma totalidad discursiva. Desde la Teoría Política del Discurso todos aquellos objetos y fenómenos que conforman la realidad social adquieren significación a través de las construcciones del orden significante. En palabras de Laclau, "todo objeto se constituye como tal en tanto objeto de discurso" (Laclau, 1985, p. 40).

Desde la perspectiva laclauniana lo social se constituye relacionalmente como una "lucha por la hegemonía” y “el terreno de constitución de la hegemonía es el discurso" (Laclau, 1985, p. 23). La disputa hegemónica se expresa a nivel óntico-fenoménico mediante la articulación retórico-política de cadenas equivalenciales de significantes que se agrupan en formaciones discursivas y la demarcación de fronteras políticas que exhiben los antagonismos constitutivos y delimitan al exterior discursivo (Laclau, 1993). En determinada coyuntura histórica, el deslizamiento de significados de la lucha hegemónica se detiene y condensa en torno a ciertos significantes (tendencialmente) vacios que "se refieren a la cadena equivalencial como totalidad" (Laclau, 2005, p. 125) y actúan como puntos nodales (puntos de capiton, en los términos lacanianos). Estos significantes primordiales logran despojarse de sus contenidos particulares y universalizar, de un modo tendencial, su inherente particularismo para encarnar, simbólicamente, el orden comunitario ausente y hegemonizar el espacio social (Laclau, 1996, 2005). Según Laclau, la operación hegemónica consiste en esta "relación por la que un contenido particular asume, en un cierto contexto, la función de encarnar la plenitud ausente" (Laclau, 2014, p. 64).

A partir de estos conceptos, esta investigación coloca el eje en el análisis textual-escrito de los significados adosados en la dinámica política al núcleo nodal de la hegemonía neoliberal. Como lo investigamos de forma pormenorizada en otro lugar (Fair, 2013, 2014a, 2014b, 2016), el principal éxito hegemónico del proyecto neoliberal-menemista consistió en construir un combo retórico-político que definimos como el núcleo nodal de la hegemonía neoliberal. El discurso menemista ató de un modo orgánico y necesario a la estabilidad macroeconómica (fiscal, monetaria y de precios) con el esquema de paridad cambiaria fija de la Convertibilidad, y a la estabilidad del " 1 a 1 " con las reformas y ajustes estructurales (privatizaciones, apertura, desregulación, flexibilización laboral, focalización del gasto público) como si constituyeran una unidad homogénea e indiferenciada. La Convertibilidad actuaba como llave de bóveda de la hegemonía. Esto suponía que no podía mantenerse la estabilidad y sus significaciones sociales sin la paridad cambiaria fija y sin la profundización de las reformas estructurales y el ajuste fiscal. Además, cualquier alternativa devaluacionista significaba el retorno al caos de la hiperinflación. En el marco de una estabilidad fáctica y de la profundización efectiva de las reformas neoliberales, la Ley de Convertibilidad se constituyó políticamente en un Plan de Convertibilidad y el 1 a 1 devino, como producto de la construcción hegemónica exitosa del menemismo, en una metáfora y símbolo de la estabilidad económica y social (Fair, 2007, 2013, 2014a, 2014b).

El éxito hegemónico del proyecto neoliberal-menemista se expresó en un desvanecimiento (tendencial) del macrodiscurso Nacional-Popular. Esta formación discursiva agrupaba a finales de los 80 a una pluralidad de referentes heterodoxos que asumían un fuerte antagonismo frente a las políticas económicas y los valores del paradigma neoliberal. La eficacia hegemónica se manifestó, además, a través de un amplio e intenso consenso social entre los principales actores de poder (empresarios, banqueros, economistas, periodistas y editorialistas de los medios de comunicación, sindicalistas, referentes de las principales fuerzas político-partidarias, eclesiásticos y del establishment internacional) en torno al núcleo nodal de la hegemonía neoliberal y, como consecuencia de ello, sobre la imposibilidad de devaluar la moneda. Este consenso básico logró convertir a devaluación en un significante tabú, contracara del valor indiscutido de la estabilidad, y desdibujó la 
construcción y articulación de un programa alternativo (Fair, 2013, 2014a, 2014b). En una muestra de la solidez del consenso básico en torno al núcleo orgánico, el 24 de octubre de 1999 un gobierno de signo contrario al menemismo, la Alianza, llegó al poder con la promesa de mantener vigente la Convertibilidad.

Como señala Laclau, "la función de fijación nodal nunca es una mera operación verbal, sino que está inserta en prácticas materiales que pueden adquirir fijeza institucional” (Laclau 2005, p. 138). Dada la existencia de múltiples posicionamientos y heterogéneas vías de organización institucional y de acción social de los actores políticos que construyen y disputan por la hegemonía, así como la pluralidad de conflictos y antagonismos que atraviesan al conjunto de las organizaciones que los agrupan (Beltrán 2006, pp. 201 y ss., 2011, pp. 223-225), los discursos textuales de los agentes políticos se analizan en términos de actores individualizados y desde sus formas de organización colectiva en determinadas agrupaciones que los nuclean a nivel institucional, sedimentando sus posiciones.

Por último, esta investigación incluye el análisis de algunos aspectos concernientes a las modalidades de enunciación política. De manera particular, se identifican, de un modo relacional, diferentes intensidades graduales de vinculación de los agentes con aquello que enuncian. Teniendo en cuenta que "el sentido de toda intervención discursiva debe ser concebido como diferencia respecto a sus condiciones de producción y de recepción" (Laclau, 1985, p. 39), este modo de abordaje permite acceder, desde una perspectiva comparada, a algunos indicios de la recepción social del discurso e indagar en la dimensión del impacto o la eficacia hegemónica. El análisis de la eficacia interpelativa se relaciona con la ponderación del grado relativo de éxito performativo de las interpelaciones de los exponentes políticos situados por el analista del discurso como referentes centrales en la construcción de la hegemonía, sobre aquellos actores ubicados estratégicamente en posición de interpelados (sin que ello implique negar su capacidad interpelativa activa) (Fair, 2013, 2014b, 2017).

\subsection{Selección del corpus y fuentes de la investigación}

Teniendo en cuenta que, desde la Teoría del Discurso y las Identidades Políticas, toda hegemonía se constituye de un modo relacional, el recorte del corpus analiza los discursos de una multiplicidad de actores políticos clave (actores de poder con elevada fuerza performativa atribuida) que corporeizan la disputa por la hegemonía, durante la crisis de diciembre de 2001. La investigación empírica se enfoca en los discursos políticos que refieren explícita o implícitamente a los significantes Convertibilidad, estabilidad, devaluación y dolarización. El motivo de esta elección se debe a que, como lo indicamos, estabilidad se constituyó desde 1991 en el significante (tendencialmente) vacío que simbolizó el orden comunitario ausente y estructuró a la hegemonía neoliberal en la Argentina. La estabilidad, a su vez, se hallaba encadenada retóricamente a la Ley de Convertibilidad y, como consecuencia de esta sólida articulación (anudada al mismo tiempo a las reformas estructurales y sus significados adosados), al consenso básico sobre la imposibilidad de devaluar la moneda. En cuanto a los proyectos dolarizadores y devaluacionistas, su análisis discursivo resulta relevante para examinar la construcción de las alternativas políticas al modelo de Convertibilidad durante la crisis del 2001. El análisis relacional de los posicionamientos y disputas de sentido de los actores políticos clave en torno a estos significantes primordiales permite acceder, además, a algunos indicios del grado de eficacia hegemónica de los exponentes institucionales del oficialismo.

En ausencia de lineamientos metodológicos para la investigación social empírica desde la teoría laclauniana de la hegemonía (Howarth, 2000), la estrategia metodológica para la construcción del corpus se basa en un corte sincrónico que escoge a la restricción de los depósitos de los ahorristas conocido como "Corralito" como un acontecimiento político que generó como efecto una fuerte "dislocación" (Laclau, 1993) en la disputa hegemónica. Este efecto dislocador impactó en las construcciones de sentido y en los posicionamientos parcialmente sedimentados de los principales agentes políticos. El recorte temporal se delimita entre el día inmediatamente previo a la instauración del bloqueo (30 de noviembre de 2001) y el 12 de diciembre. Ello 
permite realizar un análisis intensivo y profundo de los discursos en pugna de los principales actores de poder entre la instauración del Corralito y el momento específico en el que se iniciaron los saqueos a comercios y supermercados que concluyeron en la rebelión popular del 19 y 20 de diciembre, la renuncia de De la Rúa y el derrumbe del gobierno de la Alianza.

Las fuentes de la investigación se basan en los discursos públicos escenificados en los principales diarios de circulación nacional ${ }^{1}$ (Clarín, La Nación y Página 12). En el marco de la creciente mediatización de las sociedades y la importancia de los medios en la formación de la agenda pública ("agenda setting”) (Aruguete, 2015), la prensa escrita de alcance nacional constituye una plataforma privilegiada para analizar los posicionamientos y disputas por la hegemonía entre los actores políticos con mayor fuerza performativa atribuida (Laguado Duca, 2011, p. 42). Sin embargo, los medios gráficos forman parte, al mismo tiempo, de empresas capitalistas con fines de lucro y disponen de determinadas líneas editoriales, concepciones político-ideológicas e intereses económicos específicos (aunque discursivamente sobredeterminados ${ }^{2}$ ). Ello les permite utilizar su "capital simbólico" para amplificar o desdeñar ciertos discursos y también para posicionarse, a través de sus editorialistas y periodistas, como "representantes de la opinión pública" (Laguado Duca, 2011, pp. 43-44). En este sentido, coincidimos con García Delgado en que los mass media tienen una particular “capacidad para configurar opinión, agenda y sentido común” (García Delgado, 2003, p. 80). Esto supone considerar que los periodistas y editorialistas de las empresas de medios gráficos, al igual que los economistas que apelan al saber "experto", los operadores financieros y los empresarios con poder económico y capacidad de lobby (Beltrán, 2006), son actores políticos (es decir, actores de poder) clave que construyen activamente hegemonía (Laguado Duca, 2011, p. 43). La decisión teórico-metodológica de analizar de una forma simultánea tres diarios de alcance nacional con posiciones ideológicas heterogéneas entre sí permite sortear el recorte político de la información y el silenciamiento o exclusión de ciertas voces que realizan todos los medios, para examinar los discursos de una multiplicidad de actores políticos que construyen relacionalmente sentido y luchan entre sí por la hegemonía. El trabajo de investigación se complementa con el uso de fuentes bibliográficas secundarias, que contribuyen a contextualizar, historizar y conceptualizar las posiciones discursivas de los agentes desde la dinámica política.

\section{Posicionamientos y disPuTAS DE SENTIDO DE LOS ACTORES POLÍ́ticos CLAVE EN TORNO A LOS SIGNIFICANTES ESTABILIDAD Y CONVERTIBILIDAD DURANTE LA CRISIS DEL 2001}

\subsection{Los defensores de la Convertibilidad y la estabilidad del modelo económico}

A finales del 2001 se asistía a una intensa disputa hegemónica en torno al modelo económico y social. Desde el espacio público-mediático se destacaban dos paquetes discursivos relativamente estructurados. El primero de ellos, de matriz ortodoxa-neoliberal, nucleaba a un conjunto de actores políticos (principalmente, referentes del gobierno de De la Rúa, economistas de fundaciones neoliberales, periodistas y editorialistas del diario La Nación, banqueros, operadores financieros y acreedores externos) que apoyaban el rumbo general de las reformas y ajustes estructurales de la Alianza y, en algunos casos, reclamaban su profundización. El segundo, de matriz heterodoxa y productivista nacional, incluía a un conjunto amplio y heterogéneo de referentes políticos (en parte, nucleados en el Grupo Productivo) que se estructuraban en defensa de la producción nacional y el trabajo y criticaban, con diferentes matices y grados de profundidad, a las políticas neoliberales y a sus efectos económicos y sociales regresivos ${ }^{3}$ (Fair, 2017).

Los principales exponentes oficiales del macrodiscurso neoliberal presentaban en esta fase un fuerte respaldo a la permanencia de la Convertibilidad. En el momento de comunicar públicamente el bloqueo de depósitos, el ministro de Economía Domingo Cavallo (en el cargo desde marzo de 2001, en reemplazo de López Murphy) sostenía que las medidas iban a "Reafirmar y profundizar la Convertibilidad, para 
darle tranquilidad a los ahorristas". Según Cavallo, se buscaba "preservar el ahorro de los argentinos y ratificar la plena vigencia de la Convertibilidad". En ese marco, el ministro de Economía aseguraba que "La intangibilidad de los depósitos y el valor del peso y del dólar están reasegurados" (Domingo Cavallo [Clarín, 01/12/2001 y 02/12/2001]). Cavallo consideraba, además, que la restricción de los depósitos financieros era una medida tomada "Claramente en defensa de los ahorros de la gente y de la estabilidad en general de la economía argentina” (Domingo Cavallo [entrevista en Página 12, 02/12/2001]).Aquellos sectores que se referían a la posibilidad de una devaluación eran nominalizados como "gente irresponsable", que creaban "rumores" y generaban "angustia en la población" y en el sector privado (Domingo Cavallo [Clarín, 01/12/2001]). Cavallo también definía a esta alteridad política como "ataques especulativos" que provenían de los "fondos buitre". Estos sectores, cuya destinación negativa era despersonificada, "buscan una devaluación" y "querían obligarnos a cerrar el sistema financiero y devaluar". Procurando generar confianza social, el ministro le pedía a la "gente" que "deje su dinero en los bancos y no preste atención a los agoreros que hablan de devaluación". Al mismo tiempo, reafirmaba, de un modo asertivo, que "No hay ningún riesgo de que se abandone el uno a uno" (Domingo Cavallo [ Página 12, 02/12/2001]) y que "Las decisiones [tomadas] destierran cualquier hipótesis de devaluación de la moneda argentina" (Domingo Cavallo [Clarín, 01/12/2001 y 02/12/2001; Página 12, 04/12/2001, p. 8). Según el ministro, la decisión de mantener el 1 a 1, a partir del bloqueo, mostraba que "Los especuladores han sido derrotados" y que "No habrá devaluación" (Domingo Cavallo [Clarín, 03/12/2001]). En palabras de Cavallo: "Esta es la mejor demostración de que nadie piensa en el Gobierno, ni nadie pensará en el futuro, abandonar la Convertibilidad" (Domingo Cavallo [Página 12, 02/12/2001]).

En los días siguientes Cavallo acentuó el respaldo asertivo a la Convertibilidad, al señalar que "La devaluación es impensable, porque el dólar no se puede devaluar y el peso es canjeable por dólares" (Domingo Cavallo, Clarin, 07/12/2001, p. 4).

Sin embargo, luego de fracasar en el intento de obtener el adelantamiento de un préstamo previsto por el FMI por 1.264 millones de dólares ( Clarín, 06/12/2001) -y frente a la masiva caída de los depósitos y de las reservas monetarias - el ministro no descartaba una alternativa final consistente en dolarizar completamente la economía. Esta medida era presentada como una opción inherente a la Ley de Convertibilidad: "No puedo decir que no va a haber dolarización, porque está prevista en la Ley de Convertibilidad y es una cuestión de elección de los argentinos. Así que no la puedo descartar" (Domingo Cavallo [Clarín, 07/12/2001]).

Según Cavallo, esta propuesta se inscribía dentro de la dinámica de funcionamiento del propio régimen cambiario: "La dolarización siempre estuvo contemplada dentro del régimen de Convertibilidad como derecho de los argentinos a manejarse con la moneda que les venga mejor o con la que se sientan más protegidos" (Domingo Cavallo, Clarín, 08/12/2001).

Sin embargo, luego de reunirse con el director gerente del FMI, Horst Kohler, el ministro de Economía sostenía que "No discutimos ni la devaluación ni la dolarización” y que existía "La necesidad de aplicar una política de austeridad" (Domingo Cavallo, Página 12, 08/12/2001, p. 3). Esta defensa del ajuste fiscal actuaba en consonancia con las condicionalidades de los organismos multilaterales de crédito para destrabar sus préstamos financieros. ${ }^{4}$

De la Rúa desde los años noventa se había convertido en uno de los principales defensores de la estabilidad monetaria (Fair, 2014a, 2014b). Este posicionamiento en defensa del núcleo básico del modelo se mantuvo inalterable durante la campaña presidencial de 1999 y continuó una vez electo como Presidente (Pousadela, 2003, p. 142; Novaro, 2006, p. 272 y ss.; Morresi, 2008, p. 94; Castellani y Szkolnik, 2011). Durante la fase de crisis terminal del modelo de Convertibilidad De la Rúa dejaba en claro, desde una modalidad asertiva, que "La paridad cambiaria entre el peso y el dólar se mantendrá firme como hasta ahora". Además, procuraba "llevar tranquilidad a los mercados, porque desde el Gobierno estamos trabajando bien". En ese marco, rechazaba los rumores de una salida del 1 a 1 , al señalar que "Siempre se echan a circular falsas versiones, que quedan desvirtuadas por los hechos” (Fernando de la Rúa [Clarín, 01/12/2001]). En el momento de anunciar 
el bloqueo de depósitos, el Presidente reafirmó: "No hay devaluación" y "se mantiene la Convertibilidad y la estabilidad peso-dólar" (Fernando De la Rúa, La Nación, 02/12/2001). Frente a las consultas periodísticas sobre el destino del tipo de cambio, el Presidente sostuvo que "Según la Convertibilidad, un peso equivale a un dólar" (Fernando De la Rúa, Página 12, 02/12/2001).

En los días siguientes, De la Rúa mantuvo una posición favorable a la "negociación" financiera con el FMI aunque, a diferencia de Cavallo, destacó que la Argentina "No va a devaluar ni a dolarizar" (Fernando De la Rúa, Clarín, 08/12/2001). Según el Presidente, su gobierno no iba a implementar "ni [una] devaluación ni [una] dolarización": "Una devaluación sería de consecuencias muy graves y negativas. En cuanto a la dolarización, rige la Convertibilidad, de modo que quienes tienen un peso pueden cambiarlo por un dólar" (Fernando De la Rúa, Clarín, 07/12/2001, p. 4).

Juan Pablo Baylac sostenía que mediante la restricción de los depósitos "se refuerza la Convertibilidad y se garantiza el resultado del canje de la deuda". El vocero presidencial consideraba que estas medidas eran "muy importantes, porque tienden a asegurar el sistema financiero" (Juan Pablo Baylac, Página 12, 02/12/2001). De este modo, "las decisiones fueron destinadas a garantizar la estabilidad”. Según Baylac, si no se tomaban las medidas económicas, "se hubiera disparado el precio del dólar" y provocado una devaluación "de hecho" de la moneda. En consonancia con los dichos de De la Rúa, el vocero oficial ratificaba que "no va a haber devaluación y no va a haber dolarización" (Juan Pablo Baylac, La Nación, 02/12/2001). Jorge de la Rúa, ministro de Justicia, coincidía en que "las medidas son en resguardo del sistema financiero y de la Convertibilidad” (Juan Pablo Baylac, Página 12, 02/12/2001).

Durante los años noventa la mayoría de los economistas de las fundaciones neoliberales (en particular, del CEMA, FIEL y Fundación Mediterránea), al igual que los consultores internacionales y los acreedores, expresaron un apoyo general al modelo de Convertibilidad, que acompañaron con reclamos puntuales para profundizar el ajuste ortodoxo y mantener el estricto equilibrio de las cuentas públicas (Aronskind, 2007, 2008; Morresi, 2008; Fair, 2013, 2014a; Heredia, 2014; Nemiña, 2014, pp. 217-218). En la fase de crisis terminal del modelo la mayor parte de estos actores políticos clave acordaban en apoyar el salvataje al sistema financiero del Corralito como señal de respaldo a la Convertibilidad (Carlos Melconián y José Luis Blanco, Clarin, 03/12/2001). Rafael Ber, operador financiero de la consultora Argentine Research, sostenía que las medidas oficiales contribuían a generar "un clima de estabilidad para el sistema financiero" y que ayudaban a "mantener la Convertibilidad y preservar los ahorros" (Rafael Ber, La Nación, 02/12/2001). Desde el orden internacional el Subsecretario del Tesoro de Estados Unidos, John Taylor, afirmaba que "Argentina ha dado pasos importantes para enfatizar que quiere continuar con su Convertibilidad” y que "va a haber más fondos de los bancos para reforzar la fortaleza del sistema cambiario, sin devaluar" (John Taylor, Página 12, 04/12/2001, p. 6). Algunos de estos referentes políticos de la ideología neoliberal procuraban profundizar el ajuste fiscal para preservar el modelo. En este sentido, el economista ortodoxo Roberto Alemann partía del diagnóstico de la falta de "credibilidad" en la economía y pedía "conservar el uno a uno". Pero al mismo tiempo dejaba en claro que "La única opción es bajar el gasto público y subir la recaudación” (Roberto Alemann, Clarín, 07/12/2001). En la misma línea, el representante técnico del FMI en el país, John Thornton, sostenía que "si Argentina quiere continuar con [la] Convertibilidad, bueno, que haga los severos ajustes fiscales necesarios" (John Thornton, Clarin, 07/12/2001). De un modo similar se expresaron otros exponentes de este organismo en los días subsiguientes (Clarín, 09/12/2001).

Entre los actores político-mediáticos, los editoriales de La Nación defendían la continuidad del sistema de Convertibilidad y reclamaban una "política económica seria y racional”, que debía "lograr el déficit cero" y "abandonar toda idea de retorno a un pasado del que parecíamos emerger hace diez años" (Editorial de $L a$ Nación, "La grave emergencia financiera", 03/12/2001). Al mismo tiempo, pedían una "buena disposición para construir consensos tendientes a definir y establecer las grandes políticas de Estado" (Editorial de $L a$ Nación, "La crisis y el orden democrático",08/12/2001). 
Los editoriales de Clarín, menos asertivas que el discurso oficial,se referían a la "incertidumbre sobre el mantenimiento de la Convertibilidad, lo cual se tradujo en huída de depósitos y caída en las reservas”. Según Clarín, esta situación había "obligado" al Gobierno "a tomar medidas drásticas con las que espera restablecer la confianza de la gente en el sistema bancario y desalentar la salida de divisas" (Editorial de Clarín, "Hora de decisiones y de consensos", 02/12/2001). En ese contexto, la voz oficial del matutino apoyaba la incautación de los depósitos de los ahorristas, ya que contribuía a "recomponer el sistema financiero" (Editorial de Clarín, "Costos de los intereses elevados", 06/12/2001).

Luego de conocerse el rechazo al adelantamiento del préstamo financiero de los organismos multilaterales, los editoriales de Clarín asumieron "el diagnóstico del FMI, según el cual el problema argentino no es cambiario, sino fiscal". Ello implicaba mantener el respaldo explícito a la continuidad del sistema de Convertibilidad. Sin embargo, al mismo tiempo reclamaban (contradictoriamente) políticas heterodoxas tendientes a "revitalizar la economía" mediante la "mejora del consumo" y la reducción del "muy elevado costo de financiamiento" de las empresas. A esto se le sumaba la búsqueda de "consensos indispensables para garantizar gobernabilidad y previsibilidad política y económica" (Editorial de Clarín, "La decisión del FMI y sus consecuencias", 07/12/2001).

Al igual que en los años noventa (Fair, 2013, 2014a), el matutino asumía en esta fase un discurso ambivalente que combinaba elementos ortodoxos-neoliberales y heterodoxos-productivistas. Pese a sus diferencias ideológicas con las posiciones ultraliberales, Clarín coincidía con los editoriales de La Nación en el apoyo a la continuidad de la Convertibilidad y en la necesidad de "buscar consensos" entre las principales fuerzas políticas y sociales para preservar la estabilidad macroeconómica. A su vez, estos significantes se encadenaban de una forma extensiva al objetivo de la "continuidad institucional" (Editorial de Clarín, "El papel de la política en horas decisivas", 09/12/2001). De este modo, la voz oficial de los principales medios gráficos del país compartían, desde diferentes modulaciones, y con diversos gradientes de estructuración, el objetivo básico de mantener la paridad cambiaria y evitar la devaluación. Aunque en esta fase la cadena de equivalencias se hacía extensible a los acuerdos de gobernabilidad y a la estabilidad institucional.

\subsection{Los discursos críticos de la Convertibilidad}

Durante los noventa los cuestionamientos públicos a las políticas neoliberales incluyeron a una pluralidad heterogénea de actores de poder y asumieron intensidades diferenciales de radicalización. Sin embargo, el éxito del 1 a 1 en estabilizar la economía y promover el crecimiento redujo la cantidad y la intensidad de los cuestionamientos políticos y amplió las adhesiones al Plan de Convertibilidad en general, y a su punto nodal en particular (Fair, 2013, 2014b). En julio de 1993 el dirigente radical Rodolfo Terragno instaló la discusión pública sobre los límites del modelo, a partir de un debate con Cavallo en el programa televisivo "Hora Clave". En aquel debate de ideas el dirigente de la UCR criticó el "yeso" de la Convertibilidad y sostuvo que el plan económico estaba "agotado". De manera simultánea, economistas heterodoxos de la Fundación de Investigaciones para el Desarrollo (FIDE) y dirigentes de la Federación Agraria y de la Confederación Rural Argentina también mencionaron abiertamente el "agotamiento" general del esquema de Convertibilidad. Pero estos actores políticos apoyaban explícita o tácitamente la estabilidad económica, por lo que no reclamaban una devaluación (Fair, 2014a, pp. 744-747 y ss.). Además, en estos años los discursos más combativos tuvieron un escaso éxito hegemónico para modificar la correlación de fuerzas.

Luego de la crisis del Tequila de diciembre de 1994, las críticas públicas al 1 a 1 se hicieron presentes con intensidad desde la voz del candidato de la UCR Horacio Massaccesi, durante la campaña presidencial de $1995 .{ }^{5}$ Sin embargo, el dirigente radical rechazaba expresamente una salida devaluacionista del modelo. Además, su discurso de campaña obtuvo un escaso éxito interpelativo en la sociedad, frente a la propuesta continuista de Menem (quien fue reelecto en primera vuelta con casi un 50\% de los votos). 
A partir de la devaluación del real de enero de 1999, y en los años subsiguientes, los cuestionamientos al "corset" (Thwaites Rey, 1999) de la Convertibilidad se extendieron entre los principales referentes de la UIA, el duhaldismo, el alfonsinismo y la dirigencia sindical, a los que se sumaban economistas heterodoxos. Pero lo hicieron desde una crítica solapada y encubierta a los fundamentos del modelo, que mantenía el apoyo a la estabilidad y no reclamaba públicamente una devaluación (Cheresky, 2003; Pousadela, 2003; Morresi, 2008; Kan, 2009; Beltrán, 2011; Castellani y Szkolnik, 2011; Heredia, 2011, 2014; Cantamutto y Wainer, 2013; Salvia, 2014; Merino, 2015).

Con la restricción forzada de depósitos de diciembre de 2001 se potenciaron y endurecieron las críticas al modelo económico y social desde la voz de dirigentes heterodoxos de las principales fuerzas políticopartidarias (entre ellos, Ricardo Alfonsín, Leopoldo Moreau, Rodolfo Terragno y Néstor Kirchner), sindicales (titulares de la CTA, la CGT y el MTA) y mediáticas (periodistas de Página 12), además de los economistas del Grupo Fénix ( Clarín y Página 12, 02/12/2001 y ss.). Sin embargo, sólo algunos de estos cuestionamientos hacían referencia explícita al núcleo medular de la hegemonía neoliberal. El eje de las críticas se ubicaba en la Convertibilidad. Página 12, por ejemplo, titulaba en su edición del 5 de diciembre "El fin de la Convertibilidad". En una nota de Julio Nudler, publicada con el título "Había algo peor que la Convertibilidad”, el periodista se refería a la virtual destrucción del sistema mítico de paridad fija:

La Convertibilidad fue. Y se marchó para no volver. Las medidas alcanzadas a partir del sábado [1 de diciembre] colocaron al régimen económico argentino en el limbo (...). El peso sigue siendo, aparentemente, convertible, pero en la práctica no lo es (...). El tope de mil [pesos] a los viajeros y la suspensión de las remesas vuelve definitivamente ilusoria la paridad 1 a 1 del peso. Si no hay acceso libre al dólar a un tipo de cambio fijo, no hay Convertibilidad (...). Todos los mitos de la Convertibilidad se han derrumbado. Su mecanismo de relojería, el autoequilibrante sistema bimonetario, la inexpugnabilidad del sistema financiero, la solidez de una banca conformada por entidades transnacionales. Todo esto resultó mentira, a partir de la destrucción de la base productiva del país, del desempleo masivo y de la corrupción incorporada como un yelmo protector de los grandes negocios (Julio Nudler, Página 12, 05/12/2001, pp. 2-3).

Estos posicionamientos políticos percibían a la Convertibilidad como un "régimen económico" atado a las reformas neoliberales y criticaban radicalmente sus efectos regresivos. No obstante, al igual que en los años noventa, no cuestionaban explícitamente el valor positivo atribuido al punto nodal estabilidad. La única excepción parcial que encontramos es la del titular de la UIA, Ignacio De Mendiguren, quien sostenía en una entrevista que "La gente abrazó la estabilidad sin ver lo que traía aparejado como costos" (Ignacio de Mendiguren, Página 12, 09/12/2001, p. 13). Sin embargo, el referente del Grupo Productivo, quien ya desde 1998 venía criticando a la Convertibilidad (Cantamutto y Wainer, 2013, p. 77), presentaba en esta última fase una crítica ponderada y parcial al modelo económico que no ponía en cuestión ni la paridad cambiaria, ni el objetivo del ajuste fiscal del Gobierno. En ese sentido, afirmaba que desde su espacio se estaba "trabajando sobre tres ideas rectoras". Ellas consistían en una reestructuración de la deuda externa, el equilibrio fiscal con un mayor compromiso por la cuestión social y mantener la Convertibilidad, aunque con una "corrección" que permitiera incrementar la competitividad del sector industrial:

La reestructuración de la deuda, porque es imposible juntar mil millones por mes para el pago de intereses; la segunda, la cuestión social. Hay que equilibrar las cuentas públicas con el tema social; y luego, la competitividad. Preservar la Convertibilidad, pero corrigiendo las desviaciones que no permiten crecer (Ignacio de Mendiguren, titular de la UIA, Página 12, 09/12/2001, p. 13).

En ese marco, lejos de una ruptura general con el programa neoliberal, en esta fase De Mendiguren asumía un discurso heterodoxo ambivalente y con una crítica matizada a los fundamentos del modelo. 


\section{Posicionamientos y disputas hegemónicas de los aCtores políticos Clave en TORNO AL PROYECTO DE DOLARIZACIÓN DE LA ECONOMÍA}

A finales de los años noventa ingresó en la escena pública una propuesta política para dolarizar en su conjunto el sistema económico, en el contexto de una economía semidolarizada de hecho. Como señala Schorr, el proyecto de dolarización general de la economía suponía acceder a una "fase superior" de la Convertibilidad que impidiera para siempre el riesgo devaluatorio (Schorr, 2001, pp. 11-12). En este sentido, se trataba de un proyecto neoliberal-conservador tendiente a extremar la Convertibilidad y a evitar a toda costa la alternativa devaluacionista. El entonces presidente Menem fue el primero que lanzó este proyecto en una reunión del Gabinete Nacional el 14 de enero de 1999, pocos días después de la devaluación del real brasileño (Castellani y Szkolnik, 2011, p. 6).

La propuesta financiera-neoliberal de dolarización económica fue presentada públicamente por el presidente del Banco Central, Pedro Pou, en unas jornadas realizadas el 6 de mayo de 1999 (Heredia, 2014, p. 266). Fue difundida en los medios de comunicación por el propio Menem y por su entonces Ministro de Economía, Roque Fernández (Castellani y Schorr, 2004, p. 70). A finales de mayo de ese año Pou hizo público de un modo detallado el plan de dolarización y expuso sobre su presunto impacto positivo sobre la productividad, el salario real y el crecimiento (Castellani y Szkolnik, 2011, p. 7).

El proyecto dolarizador era encabezado políticamente por Menem y por economistas menemistas de la fundación neoliberal Centro de Estudios Macroeconómicos (CEMA) (entre los que se encontraban el propio Pou y Roque Fernández), con el apoyo de referentes del Partido Republicano de Estados Unidos y la Universidad de Chicago y algunos miembros del FMI (Castellani y Szkolnik, 2011, p. 7; Merino, 2015, p. 154). Además, el proyecto era respaldado por sus principales beneficiarios, es decir, las firmas extranjeras a cargo de las empresas privatizadas, grupos transnacionales con activos dolarizados y banqueros locales e internacionales (encabezados por la Asociación de Bancos Argentinos, institución que agrupaba a ADEBA y ABRA) (Basualdo, 2000, 2001, 2006; Schorr, 2001; Castellani y Schorr, 2004; Schorr y Wainer, 2005; Beltrán, 2011). En octubre del 2001 la propuesta de dolarización fue considerada por primera vez por De la Rúa (quien hasta entonces rechazaba esta opción) y esbozada por Cavallo y por algunos miembros del Gabinete (Chrystian Colombo, Nicolás Gallo y Fernando de Santibáñez). Aunque al mismo tiempo generaba importantes controversias dentro de la Alianza (Castellani y Szkolnik, 2011, pp. 8-9).

Explícitamente, el discurso dolarizador aducía que con la dolarización se lograría eliminar de forma definitiva la incertidumbre cambiaria, con el consecuente descenso de la tasa de interés, lo cual supuestamente favorecería la inversión y con ello el aumento del empleo (Cantamutto y Wainer, 2013, p. 89). Implícitamente, el proyecto dolarizador tenía como horizonte perpetuar el esquema monetario-cambiario para satisfacer los intereses del capital financiero internacional y las pretensiones expansionistas de Estados Unidos, a través de la integración al Área de Libre Comercio de las Américas (ALCA) (Cantamutto y López, 2013, p. 50). A su vez, pretendía profundizar el ajuste fiscalista y las políticas de flexibilización laboral. Ello para contraer los salarios, maximizar la concentración del capital y favorecer el disciplinamiento de los trabajadores, vía el incremento de la desocupación, la fragmentación social y la explotación de la masa asalariada (Schorr, 2001, pp. 11-12).

Durante una serie de momentos políticos clave del 2001, como en las disputas sobre el Megacanje, encontramos que no se mencionaba la alternativa dolarizadora en la escena mediática (Fair, 2017). Tampoco durante las disputas públicas sobre el proyecto de Déficit Cero del mes de julio. Sin embargo, a partir del bloqueo de los depósitos reemergieron los debates en torno a esta propuesta neoliberal-conservadora tendiente a perpetuar la Convertibilidad.

Desde su difusión pública a mediados de 1999, el proyecto dolarizador había sido criticado abiertamente por los principales integrantes del Grupo Productivo y por referentes cercanos a este espacio, como Alfonsín, Terragno, Duhalde (pese a un vaivén inicial), Moreau, la Central de Trabajadores Argentinos (CTA), la 
CGT disidente de Moyano y economistas heterodoxos del Grupo Fénix (Castellani y Szkolnik, 2011, pp. 7-9; Merino, 2015). Durante la crisis terminal de diciembre del 2001 se acentuaría el rechazo unánime de los referentes heterodoxos. El líder del Movimiento de Trabajadores Argentinos (MTA), Hugo Moyano, sostenía que la restricción forzada de los depósitos constituía de hecho una "dolarización". El sindicalista de la CGT disidente vinculaba esta propuesta política con "La última etapa de la denigración nacional y el inicio de una etapa colonial para quienes defendemos la libertad, la democracia, el trabajo, la dignidad y la identidad nacional" (Hugo Moyano, Clarín, 02/12/2001). El titular de la CGT oficial, Rodolfo Daer, coincidía en el rechazo a la propuesta dolarizadora, a la que atribuía como negativa para los trabajadores (Rodolfo Daer, Clarin, 02/12/2001).

Economistas heterodoxos también acordaban en que la incautación de los depósitos representaba una dolarización de hecho de la economía, al impedir el libre intercambio de pesos a dólares. Martín Hourest, integrante de la CTA, explicaba con un lenguaje técnico que el Gobierno había realizado una "dolarización de los depósitos" para "salvar" los "activos del sistema”. Esta decisión era "el peor camino", ya que implicaba realizar una "dolarización ficcional”, en el marco de la escasez fáctica de reservas monetarias para respaldar la paridad. La alternativa consistía en establecer "un rígido control de cambios y la administración de las reservas para preservarlas" (Martín Hourest, Página 12, 03/12/2001). Una crítica similar era asumida por Claudio Lozano ( Página 12, 05/12/2001, p. 8). Los periodistas económicos de Página 12 coincidían en que, en las actuales condiciones, la dolarización era "ficticia", en el momento en que "esos dólares, por supuesto, no existen". En este sentido, Julio Nudler sostenía que "Fue demolida la Convertibilidad, que durante años fue presentada como inexpugnable" (Julio Nudler, "Otro verano loco", Página 12, 08/12/2001, p. 2).

Para los pequeños productores agropecuarios organizados, el bloqueo de depósitos parecía marcar el inicio de una dolarización total del sistema, medida que perjudicaría comercialmente al sector. El titular de la Federación Agraria, Jorge Buzzi, expresaba su preocupación por "que estos cambios sean el principio de una dolarización que congele los actuales precios relativos, que son terriblemente perjudiciales para el sector agropecuario" (Jorge Buzzi, Clarin, 02/12/2001). El presidente de la Sociedad Rural, Enrique Crotto, sostenía, con un mayor grado relativo de asertividad, que "vamos camino a una dolarización". Sin embargo, no apoyaba de forma explícita esta propuesta, sino que convocaba a "todos los empresarios" a "tomar medidas urgentes" para generar un "golpe de confianza en la Argentina" (Enrique Crotto, Clarín, 02/12/2001).

Los referentes políticos del radicalismo y del peronismo no menemista también rechazaban explícitamente el proyecto de dolarización ( Clarín, 07/12/2001). Como señalaba Ángel Rozas, jefe de bancada radical, no se trataba de un "tema técnico", sino de un asunto "ideológico". En efecto, para la dirigencia de la UCR la salida dolarizadora sería equivalente a "ceder parte de la soberanía nacional". La alternativa era continuar con el "margen de maniobra para lograr una reactivación, sin salir de la Convertibilidad" (Ángel Rozas, Clarín, $08 / 12 / 2001)$.

Una novedad de esta última fase del modelo de Convertibilidad fue la conformación del llamado Núcleo Nacional. Esta nueva convergencia política articulaba al Grupo Productivo con las dos CGT y los bancos públicos (Cantamutto y Wainer, 2013, p. 73) en una posición de rechazo irrestricto a la propuesta dolarizadora. El 8 de diciembre del 2001 los principales integrantes del Grupo Productivo (UIA, CACon y CRA) se reunieron con la CGT de Daer y juntos emitieron un documento público. El documento conjunto comenzaba señalando que en estas horas "de confusión y crisis, hay grupos interesados en dolarizar nuestra economía”, para luego rechazar esas medidas. Por un lado, sostenía que "Sólo se han dolarizado unos pocos países, que en ningún caso tienen la complejidad y magnitud del nuestro: Panamá, Palau, Micronesia, Ecuador y las Islas Marshall”. Por el otro, hacía referencia a la pérdida de "autonomía” política y "dignidad nacional”. Pero la cuestión más importante era de política económica. Se aducía que la dolarización implicaba el abandono "definitivo" de la "política monetaria" activa por parte de la Argentina y la completa subordinación a los vaivenes del "ciclo económico" de productividad de Estados Unidos: ${ }^{6}$ 
Más allá de las obvias razones de autonomía y dignidad nacional, significaría privarnos para siempre de instrumentos esenciales de política económica. Abandonaríamos definitivamente la posibilidad de tener política monetaria. La Argentina pasaría a importar definitivamente y pasivamente la política monetaria de los Estados Unidos y a depender de su fase del ciclo económico y de su aumento de productividad (Documento conjunto del Núcleo Nacional, Clarín, 09/12/2001).

El documento sostenía, además, que "no tendríamos instrumentos para defendernos de las devaluaciones competitivas del resto de un mundo que adoptó como regla los tipos de cambio flexibles". Por último, en el marco de tarifas de servicios públicos que permanecían dolarizadas desde la sanción de la Ley de Convertibilidad, ${ }^{7}$ la dolarización "consolidaría los actuales altos niveles tarifarios de los servicios públicos y sectores monopólicos”. En ese sentido, su impacto "implicaría un dramático ajuste de los gastos esenciales del Estado, desprotegiendo a los más débiles” (Documento del Núcleo Nacional, Clarín, 09/12/2001).

El texto incluía también un cuestionamiento de tipo nacionalista a la "naturaleza colonial" de la propuesta de dolarización, que "comprometía” el "presente” y el "futuro" del país. En ese marco, reclamaba que:

En la actual crisis, por desesperación de una minoría desconcertada, no cometamos el error de comprometer el presente y el futuro de nuestra Nación con una medida de naturaleza colonial que, más allá de su indignidad, agravaría la crisis (Núcleo Nacional, Clarin, 09/12/2001).

El documento concluía con el empleo de una metáfora del campo de la medicina para referirse a la pérdida de "soberanía nacional” que implicaría adoptar la dolarización. Esta medida sólo significaría una "seguridad aparente" y una "falsa medicina" que atentaría contra la "soberanía" económica y la defensa de los "intereses nacionales": Dolarizar es una medida de seguridad aparente. Es una falsa medicina. Solo servirá para dejarnos sin los instrumentos que necesita cualquier nación en crisis para manejar soberanamente su economía y preservar sus intereses nacionales (Núcleo Nacional, Clarin, 09/12/2001).

En una entrevista en Página 12, el titular de la UIA, De Mendiguren, coincidía en cuestionar fuertemente los proyectos de dolarización. Los motivos referían a una defensa de lo nacional frente a la "entrega de la moneda" y, en segundo término, a su impacto regresivo sobre la actividad económica:

Lo más preocupante es que aquí se vaya a la dolarización. Yo no comparto que esto sea la solución. Sobre todo, porque hay un tema previo a lo técnico: que sólo un país que no tiene claro su destino puede hablar de entregar su moneda. Además, está el fuerte impacto que va a tener sobre los niveles de actividad económica (Ignacio de Mendiguren, titular de la UIA, Página 12, 09/12/2001, p. 13).

De este modo, los actores empresariales y sindicales que lideraban el Núcleo Nacional convergían con economistas y periodistas heterodoxos, exponentes del peronismo no menemista y de la UCR y referentes de los principales medios gráficos, en un rechazo generalizado a la opción dolarizadora.

Pero el aspecto más interesante de esta última fase de la crisis del modelo de Convertibilidad es el cambio de visión de los actores políticos clave que meses atrás apoyaban de forma entusiasta la dolarización. Los economistas ortodoxos del sector menemista ahora se referían a la "inconveniencia" de dolarizar el sistema, en el marco del deterioro de las reservas y su imposibilidad técnica de cubrir el total de la circulación monetaria ( Clarín, 08/12/2001). El propio Menem, principal promotor del proyecto, sostenía que "Una cosa era dolarizar cuando el peso estaba uno a uno con el dólar. El peso evidentemente, en los hechos, se ha devaluado, porque se están pagando 1,20 o 1,30, en algunos lugares, por dólar" (Carlos Menem, Clarín y Página 12, 09/12/2001).

Una posición similar asumía Roque Fernández, ex Ministro de Economía durante la segunda presidencia de Menem y por entonces su asesor. ${ }^{8}$ Fernández sostenía que "La Convertibilidad ya se abandonó" (Roque Fernández, Página 12, 04/12/2001, p. 8). Sin embargo, luego de la negativa al préstamo acordado con el FMI, el economista del CEMA rechazaba la viabilidad de la propuesta dolarizadora original (Roque Fernández, Clarín, 09/12/2001). La escasez fáctica de reservas en el Banco Central para respaldar al 100\% la base monetaria y conservar la paridad fija había modificado las posiciones políticas, al compás del cambio en las condiciones económicas. Como lo sintetizaba el periodista de Clarín Oscar Martínez: 
La dolarización parece ir perdiendo los fanáticos que supo cosechar. Y hoy sería patrimonio exclusivo de algún centro de estudios [macroeconómicos]. En la mayoría de los casos, este abandono tendría razones objetivas: algunos estudios sostienen que ya no habría la cantidad de divisas suficientes como para canjear cada peso circulante por un dólar de las reservas (Oscar Martínez, nota en Clarín, 09/12/2001).

De modo tal que, a finales del 2001, la propuesta dolarizadora original había perdido a su principal referente y ancla político y parecía reducirse a pequeños círculos minoritarios.

\subsection{El realismo político y la propuesta financiera-neoliberal de fluctuación ponderada del tipo de cambio más dolarización del menemismo}

Vimos que en diciembre de 2001 la propuesta de dolarización plena, como fase superior del esquema convertible, era cuestionada aún por sus propios promotores. Ahora bien, al analizar con mayor detalle los discursos del sector menemista, podemos apreciar que sus principales referentes mantenían ambigedades con relación a este proyecto de radicalización del orden neoliberal. Por un lado, reconocían que en esta etapa ya no existían técnicamente las reservas suficientes para preservar el " 1 a 1 " y que el tipo de cambio se manejaba, en los hechos, en torno a 1,20 o 1,25 pesos por cada dólar. Pero, por otro lado, no abandonaban esta propuesta. En este sentido, Menem volvía sobre sus pasos y sostenía en un encuentro público que no descartaba la dolarización y lo mismo hacía su asesor Roque Fernández.

Sin embargo, en un contexto de sangría de reservas, restricción financiera y falta de dólares para mantener la paridad fija, estos referentes adoptaban una visión más realista. La nueva propuesta consistía en readecuar el tipo de cambio, para luego realizar una dolarización general. Este proyecto había sido propuesto en los primeros días de noviembre de 2001 desde inversores privados de la banca internacional (Morgan Stanley, Lehmann Brothers y ENCA, entre otros). También era apoyado por algunos sectores del FMI que pugnaban por acelerar el default y la dolarización total (Merino, 2015, p. 238). A nivel local, contaba con el respaldo político de los economistas neoliberales del CEMA Carlos Rodríguez, Pedro Pou y el propio Roque Fernández. ${ }^{9}$ Concretamente, la estrategia implicaba mantener inalterable los fundamentos del orden financiero-neoliberal, pero reacomodando el tipo de cambio en un nuevo rango, para luego dolarizar en su conjunto la economía. ${ }^{10}$ Como señalaba Fernando Losada, operador financiero de la consultora ABM Amro Bank: "Hay que ser realistas: la Convertibilidad, tal como la conocíamos en 1991, yo no estoy seguro de que exista en estos momentos" (Fernando Losada, Página 12, 09/12/2001, p. 4).

En este sentido, Menem proponía reformular, sin abandonar, la propuesta dolarizadora, para adaptarla a las nuevas condiciones económicas. En palabras del ex Presidente: "Hay que readecuar la dolarización a lo que estamos viviendo ahora" (Carlos Menem, Página 12, 09/12/2001, p. 6).

Roque Fernández sostenía que "la Convertibilidad ya se abandonó" (Roque Fernández, Página 12, 04/12/2001, p. 8). Sin embargo, el proyecto dolarizador continuaba vigente para garantizar estabilidad y seguridad a la "gente": "La propuesta de dolarización es una iniciativa que ha sido ampliamente apoyada por todos y siempre fue un proyecto de Menem para darle a la gente la tranquilidad de una manera estable y segura" (Roque Fernández, Página 12, 05/12/2001, p. 11). Al mismo tiempo, agregaba que se podía salir sin problemas de la "rigidez" del 1 a 1 con pequeñas "oscilaciones" del tipo de cambio: "Es perfectamente posible salir de la rigidez de la Convertibilidad sin que se provoque una fuerte devaluación, sino sólo algunas oscilaciones" (Roque Fernández, Página 12, 09/12/2001).

Esta estrategia de oscilación relativa del tipo de cambio para luego realizar una dolarización total del sistema era presentada por Roque Fernández como una alternativa frente a las devaluaciones decrecientes de la "Tablita" de José Alfredo Martínez de Hoz de finales de 1978 y la "fijación" del tipo de cambio de la Convertibilidad. ${ }^{11}$ La nueva propuesta de política económica consistía en readecuar el tipo de cambio a 
través de una "fluctuación" ponderada calculada entre un 15\% o 20\% y realizar un acuerdo con el FMI para garantizar la solvencia fiscal del modelo:

No propongo una Tablita, ni fijar un tipo de cambio, sino ir acomodando el tipo de cambio a la economía argentina. Con un acuerdo del Fondo Monetario, solvencia fiscal y un Banco Central independiente, yo me animo a decir que la fluctuación estaría en un 15\% o 20\% (Roque Fernández, Clarín y Página 12, 09/12/2001).

El reacomodamiento cambiario suponía devaluar la moneda. Sin embargo, el eufemismo de la "fluctuación" del tipo de cambio se articulaba con un programa dolarizador. Esta política, a su vez, se vinculaba con la inserción al proyecto estadounidense imperial del ALCA y con un discurso ortodoxoneoliberal que reclamaba establecer un "acuerdo" con el Fondo Monetario para conservar la "solvencia fiscal" y garantizar un "Banco Central independiente" (Roque Fernández, Clarín y Página 12, 09/12/2001). En los hechos, la propuesta de Roque Fernández y los economistas del CEMA implicaba una devaluación encubierta para ganar competitividad y luego dolarizar toda la economía. Ello con el objeto de radicalizar el ajuste fiscal y extremar el esquema convertible, imposibilitando nuevas devaluaciones. De este modo, el menemismo y sus aliados sólo buscaban realizar una corrección cambiaria para preservar el mismo orden financiero-neoliberal.

\section{Posicionamientos y disputas hegemónicas de los aCtores políticos Clave en TORNO AL PROYECTO DE DEVALUACIÓN MONETARIA}

Como lo investigamos en otro lugar, durante los noventa devaluación se convirtió en un significante tabú, en el marco de un sólido, amplio e intenso consenso social en torno al valor de la estabilidad económica del 1 a 1 (Fair, 2013a, 2014a, 2014b). Este intenso consenso colectivo sobre la continuidad de la estabilidad monetaria y la imposibilidad o inconveniencia de devaluar continuó en las elecciones legislativas de $1991^{12}$ y de 199313 y también durante la campaña presidencial de $1995 .{ }^{14}$

A partir de la devaluación brasileña y la conformación del Grupo Productivo comenzaron a hacerse presentes algunas críticas más explícitas al tipo de cambio fijo. Sin embargo, devaluación continuaba siendo un significante difícil de ser pronunciado públicamente, frente a la efectiva estabilización económica y el mayoritario apoyo popular a la continuidad de la Convertibilidad (que se expresó en el cómodo triunfo electoral de De la Rúa en octubre de 1999). Además, persistía el temor a los efectos regresivos de una salida devaluatoria en términos de un retorno al caos de la hiperinflación y/o la imposibilidad de hacer frente a las multimillonarias deudas dolarizadas del sector privado. ${ }^{15}$ De allí que los argumentos devaluacionistas, aunque se fueron haciendo cada vez más explícitos, continuaban expresándose en esta etapa con mucha cautela y de un modo predominantemente solapado y encubierto (Castellani y Szkolnik, 2011, p. 10 y ss.). Durante diferentes momentos clave del 2001 (entre ellos, los debates sobre el Megacanje y el proyecto de Déficit Cero) encontramos que los principales actores de poder del macrodiscurso productivista-nacional criticaban, con diferentes intensidades relativas, al modelo económico y social. Algunas voces minoritarias, entre ellas la de Alfonsín, cuestionaban también a la paridad cambiaria. Pero, al mismo tiempo, devaluación continuaba siendo un significante tabú (Fair, 2017).

A finales de noviembre de 2001 las principales corporaciones locales de la industria (UIA), la construcción (CACon) y el agro (CRA) que formaban parte del Grupo Productivo, a lo que se sumaba como novedad el sector bancario local (Asociación de Bancos de la Argentina y Asociación de Bancos Provinciales) organizadas en el flamante Núcleo Nacional- presentaron un documento público. El documento acordaba "respetar la Convertibilidad", "trabajar en la neutralización de las distorsiones que ha provocado la devaluación en Brasil" y promover las "exportaciones" 16 (Documento del Núcleo Nacional, Clarín, 30/11/2001). A partir de la restricción forzada de los ahorros del Corralito, la Argentina ingresó en una fase de "crisis orgánica" (Gramsci, 2008, p. 53) y arreció la desconfianza social en torno a la solidez 
del esquema cambiario. ${ }^{17}$ Sin embargo, para una porción de los actores de poder se debía mantener el esquema de Convertibilidad y consensuar políticas públicas para garantizar "gobernabilidad" y "timonear" la "crisis" (Julio Blanck, "La debilidad del gobierno y la responsabilidad del peronismo", Clarin, 01/12/2001). El objetivo central consistía en "espantar los fantasmas de la devaluación", de manera tal de "evitar males aún mayores" (Eduardo Van der Kooy, "El Gobierno, cercado por la desconfianza y el peronismo", Clarín, 02/12/2001). Como sostenía el gobernador bonaerense Carlos Ruckauf, la devaluación era económica y socialmente costosa, ya que "destruiría a las empresas que se endeudaron en dólares para modernizarse, y además costaría muchos puestos de trabajo" (Carlos Ruckauf, Clarín, 01/12/2001). Pese a sus divergencias, estos discursos antidevaluacionistas compartían el posicionamiento del significante devaluación como un peligro que acolchonaba la frontera de exclusión. Devaluación se constituía, así, en un significante que simbolizaba la "pura anti-comunidad" (Laclau, 1996, p. 79).

\subsection{Las propuestas de devaluación encubierta a través de la flotación del tipo de cambio}

En el marco de la devaluación como un significante que representaba la anticomunidad, en esta última fase se expresaban en la escena pública algunas variantes críticas de la Convertibilidad, pero que no mencionaban expresamente la necesidad de devaluar.

La primera variante consistía en flexibilizar el tipo de cambio para ir hacia una flotación cambiaria. Esta opción era propuesta por la vicepresidenta del FMI y representante de los Estados Unidos en el organismo, Anne Krueger. Krueger, cuyas ideas se inscribían dentro de la escuela neoliberal de Virginia (Morresi, 2007, p. 125), sostenía que "para solucionar sus problemas de fondo (la) Argentina tiene que entrar en una flotación cambiaria” (Anne Krueger, Clarín, 07/12/2001). Ello implicaba, en contraste con otros referentes del FMI, apoyar una devaluación encubierta de la moneda, como precondición para dejar al tipo de cambio flotante.

${ }^{18}$ Sin embargo, no dejaba en claro si pretendía ir hacia una flotación libre o administrada. ${ }^{19}$ Además, las recomendaciones de Krueger se asociaban a los intereses fiscalistas del FMI para devaluar y reestructurar la deuda (Nemiña, 2014, p. 236). De este modo, su propuesta, planteada inicialmente el 23 de noviembre de 2001, se inscribía dentro del proyecto financiero-neoliberal-imperialista de devaluación con dolarización plena (Merino, 2015, p. 239).

Una segunda alternativa dentro del planteo de flotación cambiaria era la propuesta de la Secretaria de Comercio, Débora Giorgi. Giorgi proponía utilizar un "tipo de cambio flexible” para ganar competitividad y promover el comercio con los países del Mercosur, en lo que parecía ser una defensa de una canasta de monedas que incluyera al real brasileño. Recordemos que en junio de 2001 el Gobierno había sancionado por ley un proyecto inicial de "flexibilización" del tipo de cambio mediante la incorporación del euro en la paridad entre el peso y el dólar (Bonvecchi, 2002, p. 150). Este esquema de Ley de Convertibilidad "ampliada" introducía un sistema cambiario dual, con un tipo de cambio con base a una canasta dólar-euro, junto con una política de aranceles y reintegros destinados a mejorar la rentabilidad de los exportadores, y un tipo de cambio financiero fijo en 1 a 1 frente al dólar. La ley estipulaba que, en el momento en que el dólar y el euro valiesen lo mismo, el peso pasaría a estar respaldado por estas dos divisas (Peralta Ramos, 2007, pp. 353 y 361). Sin embargo, como ello nunca ocurrió, la medida nunca entró en vigencia (Nemiña, 2014, p. 230).

En ese entonces, la UIA había sostenido que la Convertibilidad "ampliada" debía ser transitoria y adujo que la medida era insuficiente. Como alternativa propuso establecer una canasta de monedas que, además del euro, incluyera al devaluado real brasileño para acortar la brecha cambiaria con el país vecino (Cantamutto y Wainer, 2013, p. 88). Giorgi retomaría este reclamo, que suponía establecer una depreciación del tipo de cambio sustancialmente mayor, al sostener que "sin el real en el tipo de cambio de exportación argentino, no podemos competir con Brasil" (Débora Giorgi, Clarín, 09/12/2001). Sin embargo, esta propuesta de devaluación encubierta sería rápidamente descartada por el propio Gobierno. Ello, luego del rechazo del 
ministro de Economía brasileño, Pedro Malan, quien declaraba que "Brasil no acepta el ingreso del Real en el tipo de cambio para exportación de la Argentina” ${ }^{20}$ (Pedro Malan, Clarín, 09/12/2001).

Una alternativa heterodoxa más radicalizada, pero que contaba con una escasa visibilidad y fuerza pública, era la propuesta de los economistas del Grupo Fénix. Estos sectores, nucleados inicialmente en la Fundación de Investigaciones para el Desarrollo (FIDE), desde la primera mitad de la década del 90 venían destacando el agotamiento de la Convertibilidad y reclamando algún tipo de "corrección" del tipo de cambio para construir un modelo de país alternativo al orden neoliberal (Fair, 2014a, p. 750). Durante los primeros años de la Alianza los economistas heterodoxos ligados a este espacio mantuvieron una intensa crítica a la Convertibilidad por su dependencia del ingreso permanente de divisas (en particular, a través del endeudamiento externo), la creciente pérdida de competitividad de la economía en condiciones de sobrevaluación cambiaria y sus efectos regresivos sobre las condiciones laborales. Algunos de estos economistas (Conesa, Curia, Frenkel, Valle) sostuvieron en minoría la necesidad de abandonar la Convertibilidad, aunque no reclamaban abiertamente una devaluación (Heredia, 2014, pp. 260-287).

Héctor Valle, director del FIDE, había sostenido, ya en marzo de 1993, que "si bien el tipo de cambio probó ser un arma exitosa, hoy muestra signos de agotamiento" (Fair, 2014a, p. 744). En octubre de 1998 Valle reclamó la implementación de un sistema de "fluctuación por bandas" como el utilizado en Brasil, ante el silencio generalizado de sus colegas (Heredia, 2014, p. 262). En una entrevista realizada por Página 12 en plena crisis de diciembre del 2001 el mismo Valle cuestionaba la viabilidad técnica de la propuesta dolarizadora, ya que:"Hay un problema severo para implementar la dolarización, que es que las reservas del Banco Central no alcanzan más que para cubrir el 14\% de los depósitos que hay en el sistema bancario" (Héctor Valle, Página 12, 05/12/2001, p. 6).

La alternativa al modelo económico-financiero vigente debía aplicar "políticas keynesianas” expansivas, en un marco de "flexibilización" del tipo de cambio:

La Argentina tiene que plantearse la construcción de una política económica alternativa. La estrategia que lleva adelante el Gobierno sólo se preocupa por garantizar la situación del sistema financiero, sistema que, por otra parte, en buena medida está quebrado. Es preciso avanzar en otra dirección. Como dice el Plan Fénix, hay que aplicar las recetas tradicionales para que una economía salga de la depresión, con políticas keynesianas, en un contexto de flexibilización cambiaria (Héctor Valle, director de FIDE, Página 12, 05/12/2001, p. 6).

En esas condiciones, el economista del Grupo Fénix apoyaba la propuesta de implementar un sistema de flotación del tipo de cambio. Este nuevo esquema cambiario debía ser acompañado con políticas estatales expansivas de la inversión pública para promover el desarrollo nacional, protecciones para los ahorristas y los sectores endeudados y una reestructuración de la deuda externa:

Hay que ir a un régimen de flotación del tipo de cambio, con desdolarización y políticas destinadas a proteger a los depositantes y a los endeudados. Paralelamente, la política económica tiene que atender tres puntos muy importantes: una política de ingresos, una política de inversión pública destinada a potenciar el desarrollo, y la reprogramación de la deuda (Héctor Valle, FIDE, Página 12, 05/12/2001, p. 6).

Si bien no se refería expresamente a la devaluación, Valle sostenía que salir del esquema del 1 a 1 mediante un sistema de flotación "generaría un cambio en los precios relativos a favor de sectores transables". En efecto, al flexibilizar la moneda se restringirían las importaciones, se fomentaría la industria nacional y se promovería a mediano plazo un fuerte incremento de las exportaciones productivas, de manera tal que: "Habría un primer impacto de sustitución de importaciones, un segundo de ingreso de inversiones para sectores productivos que se vuelven atractivos y un tercero, a mediano plazo, de fuerte aumento de las exportaciones" (Héctor Valle, Página 12, 05/12/2001, p. 6).De este modo, la estrategia de flotación cambiaria, junto con la reprogramación de la deuda externa y el incremento de la inversión pública, incentivarían la exportación hacia los países del Mercosur y el desarrollo productivo nacional. 
Esta modulación heterodoxa radicalizada convergía con las posiciones de la CTA de De Gennaro y la CGT disidente de Moyano sobre la necesidad de construir un programa globalmente alternativo al orden financiero-neoliberal, en lugar de meras correcciones parciales para ganar competitividad (como proponían los principales referentes empresariales del Núcleo Nacional). En esta línea, Claudio Lozano criticaba la "hipocresía neoliberal" y promovía un proyecto productivo alternativo que debía basarse en la redistribución progresiva del ingreso y el desarrollo del mercado interno. Ello a través de una "desvalorización" del peso, la desdolarización de las tarifas, la reducción de las tasas de interés y el fin del modelo de especulación financiera. Se trataba de construir:

Una estrategia que potencie el uso del peso desvalorizando la economía nacional, que redistribuya los ingresos ampliando el mercado interno de demanda masiva y que replantee la estructura de precios, bajando tasas de interés y tarifas públicas, y abriendo paso a una nueva estrategia productiva (Claudio Lozano, "Hipocresía neoliberal", nota en Página 12, 05/12/2001).

El economista Aldo Ferrer, histórico referente del campo heterodoxo, presentaba una posición similar. Ferrer consideraba que "hoy la Convertibilidad es una ficción, porque las reservas del BCRA representan entre el 10\% y el $15 \%$ del total de activos convertibles en dólares". La alternativa consistía en:

Pasar el sistema a pesos, en el marco de una nueva política macroeconómica que debe flexibilizar la política cambiaria para favorecer a la inmensa mayoría del país que está ligada al trabajo y a la producción y que no participa de los sectores especulativos vinculados a rentas extraordinarias (Aldo Ferrer, entrevista en Página 12, 09/12/2001, p. 6).

Sin embargo, mientras que las propuestas radicalizadas de redistribución progresiva del ingreso eran ignoradas por los empresarios que lideraban el Núcleo Nacional, las propuestas de devaluación con flotación cambiaria eran cuestionadas por algunos referentes de poder de este mismo espacio. En un encuentro del Núcleo Nacional, Mario Llambías, vicepresidente de la CRA, sostenía que la estrategia de flotación del tipo de cambio no era viable políticamente: "Creemos en la necesidad de mejorar la competitividad y alentar la exportación, pero no vemos que el gobierno tenga suficiente credibilidad como para ir a una flotación cambiaria” (Mario Llambías, Página 12, 11/12/2001, p. 2).

De este modo, se mantenían las intensas disputas ideológicas en torno a los proyectos alternativos, incluso dentro de las posiciones heterodoxas. Ello impedía articular un programa alternativo con pretensiones universalizantes.

\section{Los discursos Críticos, PERO NO DEVALUACIONISTAS NI DOLARIZAdores: ENTRE LA DESCRIPCIÓN DE LA COYUNTURA, LAS PROYECCIONES A FUTURO Y LA PROFECÍA APOCALÍPTICA}

$\mathrm{Al}$ igual que en otros momentos clave del gobierno de la Alianza (Megacanje, ley de Déficit Cero), durante la crisis de diciembre del 2001 diferentes referentes políticos criticaban con intensidad al modelo económico y social, pero sin apoyar explícitamente las alternativas devaluacionistas y dolarizadoras y, en ocasiones, rechazando también el peligro de default. Uno de los principales críticos del modelo de acumulación era el senador radical Leopoldo Moreau, quien se refería a "la ficción de que un peso es un dólar". Moreau acusaba al "mesianismo de Cavallo" de ser el responsable de llevar al país a "una crisis económica de carácter terminal" que desembocaba en "una cesación de pagos encubierta, una devaluación encubierta y una dolarización encubierta" (Leopoldo Moreau, La Nación y Página 12, 02/12/2001). Sin embargo, Moreau no reclamaba una devaluación de la moneda para salir de esa "ficción", sino que se limitaba a describir la situación existente y lo que podía suceder a futuro.

Terragno coincidía en criticar fuertemente a un modelo "monetarista" que "destruyó industrias, destruyó empleos y al final terminó destruyendo la moneda que decía defender". Aunque al mismo tiempo reconocía que no existía un programa alternativo viable: "Ahora discuten si mantener la Convertibilidad en terapia 
intensiva, devaluar o dolarizar, pero ninguno tiene un plan de desarrollo económico" (Rodolfo Terragno, Página 12, 12/12/2001, p. 9).

El senador Gioja, por su parte, sintetizaba la visión del PJ no menemista sobre el tipo de cambio, al afirmar que "No creo que nadie esté pensando en devaluar ni en dolarizar" (José Luis Gioja, Clarín, 07/12/2001).

Los discursos heterodoxos agrupados en el Núcleo Nacional coincidían, pese a sus diferencias internas, en evitar la opción devaluacionista y, en particular, en impugnar la opción dolarizadora. Desde el lado de los representantes de los trabajadores, Rodolfo Daer (CGT) y Víctor de Gennaro (CTA) criticaban radicalmente al modelo de "ajuste" del Gobierno. Daer sostenía que "Cavallo se ha agotado, su plan económico se ha agotado" (Rodolfo Daer, Página 12, 11/12/2001, p. 9). De Gennaro afirmaba que "el principal enemigo de todos es el ajuste y la represión", ya que "lo único que hacen es profundizar la recesión, aumentando la desocupación y la pobreza". El titular de la CTA sostenía que: "Lo que queremos es cambiar el modelo económico, político, social y cultural del sálvese quien pueda"(Víctor De Gennaro, Página 12, 08/12/2001, p. 13). Se trataba de mostrar que "existe un modelo alternativo al ajuste perpetuo" (Víctor De Gennaro, Clarín, 07/12/2001). Sin embargo, ambos dirigentes rechazaban cualquier intento de "dolarización o devaluación del peso" (Rodolfo Daer y Víctor De Gennaro, Clarín, 02/12/2001; Página 12, 08/12/2001).

Luego que el FMI anunció el rechazo al adelantamiento del préstamo financiero al Gobierno, Clarín convocó a un grupo de economistas a realizar sus diagnósticos sobre el presente y las proyecciones sobre el futuro del país. Para Jorge Schvarzer las medidas tomadas a partir del Corralito eran "angustiosas respuestas a la coyuntura" para "ganar tiempo". Además, estaba faltando elaborar una "estrategia de largo plazo". Sin embargo, el economista sostenía que "la devaluación no ayudaría en nada". Incluso, afirmaba que sería contraproducente, ya que "encarecería la deuda pública". A su vez: "El efecto redistributivo complicaría la reactivación y, en términos comerciales, no tendría ningún efecto, ya que se exporta todo lo que se puede, y las importaciones están en el mínimo de los últimos diez años" (Jorge Schvarzer, Clarín, 07/12/2001). De este modo, Schvarzer cuestionaba al Régimen de Convertibilidad, aunque rechazaba la opción de la devaluación. Ello implicaba describir los penosos efectos del modelo económico y reclamar una "estrategia de largo plazo", pero sin promover una salida devaluacionista, ni formular un programa alternativo.

Martín Redrado, de la Fundación Capital, sostenía que "la actual dinámica es simplemente inconsistente. No se puede tener libertad de movimientos de capitales, política fiscal expansiva y tipo de cambio fijo". En ese marco, sostenía que a la Convertibilidad "no le veo futuro". Sin embargo, no reclamaba una devaluación. En cambio, realizaba proyecciones a futuro y sostenía que la opción más factible era el "default más dolarización". Tampoco descartaba que Cavallo, "llegado el caso, opte por la tercera D", en referencia a la "devaluación” (Martín Redrado, Clarín, 07/12/2001). Ricardo Delgado, director de la consultora Ecolatina, sostenía que la decisión del FMI de rechazar el préstamo financiero "expresa el creciente consenso de que la Convertibilidad está acabada”. No obstante, en lugar de elaborar una alternativa programática, se limitaba a elucubrar en torno a las posibles respuestas por parte del Gobierno y concluía que "el escenario más factible" era el de "las tres D" (Ricardo Delgado, Clarín, 07/12/2001). Héctor Gambarotta, ex Subsecretario de Industria, describía "tres escenarios posibles": "dolarización uno por uno, devaluación más dolarización y devaluación más flotación”, aunque sólo cuestionaba explícitamente a las alternativas dolarizadoras (Héctor Gambarotta, Clarín, 07/12/2001). Desde el orden internacional, un editorial de Wall Street Journal sostenía que "la crisis de Argentina está llevando a un momento decisivo y parece dirigirse hacia una dolarización o hacia una devaluación" (Wall Street Journal, en Página 12,05/12/2001, p.3). Mientras que El País de España afirmaba que las medidas oficiales "sólo pretenden atajar una situación monetaria angustiosa" y que "tampoco alejan el riesgo de la temida devaluación” (El País, en Página 12,05/12/2001, p. 3). Sin embargo, estos actores de poder no reclamaban dolarizar o devaluar, sino que sólo se hacían eco de los rumores existentes.

Con la decantación de las medidas, los periodistas de Clarín también mostrarían una preocupación sobre si era "viable" el "plan económico argentino de déficit cero y Convertibilidad" (Marcelo Bonelli, nota en Clarín, 
07/12/2001). En el contexto de una economía que "llegó en su descenso a uno de los últimos escalones", algunos periodistas del matutino expresaban sus "dudas en torno a la solidez del esquema en que se apoya la Convertibilidad" y sintetizaban las alternativas en danza en la escena pública (Jorge Velázquez, nota en Clarín, 07/12/2001). Desde una crítica con connotaciones más profundas, Julio Blanck sostenía que la Convertibilidad, luego de ser "el gran eje organizador de la sociedad durante diez años", ahora mostraba "señales de extenuación":

Hoy la convertibilidad -que fue el gran eje organizador de la sociedad durante diez años- da señales de extenuación. Quedaron lejos los días dorados de la ilusión de Primer Mundo y ahora asoman con crudeza la desocupación récord, una recesión de cuatro años, el $40 \%$ de los argentinos bajo la línea de pobreza y la distribución del ingreso más desigual que se tenga memoria (Julio Blanck, "Una democracia menor de edad", nota en Clarin, 09/12/2001).

A la hora de pensar los escenarios a futuro se podía terminar, de acuerdo a los "rumores" existentes, en el "camino inevitable a la dolarización" (Jorge Aulicino, "Mensajes del gobierno al peronismo en un día difícil", nota en Clarín, 06/12/2001), o bien en el "fantasma de la devaluación” y la "virtual convocatoria de acreedores" (Jorge Velázquez, nota en Clarín, 07/12/2001).

Lo interesante de estas posiciones políticas es que cuestionaban, con diversas intensidades relativas, a la Convertibilidad. Además, explicitaban las alternativas devaluacionistas y dolarizadoras, en ocasiones junto con la posibilidad de cesación de pagos de la deuda. Sin embargo, la caracterización se limitaba a describir y constatar su visión sobre la crisis económica y social, o bien a hacer presunciones sobre el futuro próximo, atribuido invariablemente como negativo. Ello los conducía a referirse a los efectos regresivos que traería un escenario signado por cualquiera de estas tres opciones, pero sin justificar ninguna de ellas. En contraste con el optimismo oficial, y lejos de reclamar la devaluación o una dolarización, estos actores de poder solo simbolizaban sus temores y hacían proyecciones sobre el destino de la economía y del país mediante el empleo de metáforas pesimistas vinculadas a la aplicación de "parches" en la "herida" del paciente (la economía argentina). Estos parches pretendían "postergar", por poco tiempo, un "desenlace" que era percibido como "traumático". Como lo sintetizaba un periodista de Clarin:

Los parches que Cavallo va colocando sobre la herida parecen postergar siempre un día más un desenlace que casi todos suponen traumático. Sin embargo, todavía cuesta imaginar con precisión cuál será el escenario más probable para el aterrizaje. La dolarización aparece como una de las alternativas con mayor cantidad de chances. Así lo admitió ayer el Ministro de Economía en una conferencia de prensa, donde marcó una diferencia tajante entre la adopción del dólar como moneda propia y otras opciones tanto o más controvertidas, como la devaluación (Jorge Velázquez,nota en Clarín, 07/12/2001).

De este modo, estos exponentes políticos actuaban como caja de resonancias de los "rumores sobre una posible dolarización o una eventual devaluación", que "sólo sirven para agigantar el temor de que, por uno o por otro camino, se avecina algo peor" (nota no firmada, Clarín, 08/12/2001). El periodista Oscar Martínez sintetizaba el panorama existente, al señalar que: "Si la Convertibilidad está para muchos agotada, la dolarización, al menos en su fórmula original (canjear cada peso en circulación por un dólar) es poco viable para otros" (Oscar Martínez, nota en Clarín, 09/12/2001). En ese marco, Martínez planteaba "la pregunta sobre la salida de la crisis", para luego sostener que "el régimen monetario por sí mismo no garantiza la solución” (Oscar Martínez, Clarín, 09/12/2001). El empleo del adverbio “por sí mismo” implicaba validar tácitamente a la Convertibilidad, para luego buscar algún tipo de salida no devaluacionista. En otros casos, parecía mantenerse devaluación como tabú. En este sentido, el periodista Mariano Pérez de Eulate se hacía eco del temor a enunciar en público la palabra devaluación entre los economistas: "Algunos de los economistas hablan de la inevitabilidad de una devaluación, palabra maldita que ninguno dirá ante los micrófonos" 21 (Mariano Pérez de Eulate, nota en Clarín, 07/12/2001).

Los editoriales de Clarín también comenzaban a replicar la discusión política sobre "los caminos a seguir" frente a la crisis terminal del modelo. En el editorial del 9 de diciembre el matutino sintetizaba, desde una modalidad descriptiva, las tres posiciones que se hallaban en el centro de la escena pública: 
A consecuencia de la crisis se ha planteado en los últimos días, y cada vez con más énfasis, la discusión sobre los caminos a seguir en caso de llegar a una cesación de pagos, siendo las principales la dolarización, la devaluación y la devaluación con dolarización(Editorial de Clarín, 09/12/2001).

La voz oficial del diario, sin embargo, rechazaba tanto a las alternativas dolarizadoras como a las devaluacionistas, ambas por sus efectos negativos:

La devaluación es una alternativa temida tanto por quienes tienen deudas en divisas, como por buena parte de la ciudadanía, que tiene presente las épocas de inestabilidad cambiaria e inflación. La dolarización aventaría estos fantasmas, pero a cambio de provocar una fuerte restricción en la liquidez interna, un golpe recesivo y una pérdida definitiva de soberanía monetaria y cambiaria (Editorial de Clarín, 09/12/2001).

De acuerdo a Clarín, "la dolarización o la devaluación tendrían también consecuencias recesivas, políticas y sociales de enorme gravedad". La alternativa consistía en buscar un "consenso" entre las fuerzas políticas y sociales para que se "minimicen los daños del ajuste" (Editorial de Clarín, "Un nuevo programa de ajuste fiscal”, 11/12/2001, p. 22).

De este modo, aunque Clarín mencionaba las principales opciones en danza y pretendía elaborar una "salida" a la "crisis", al mismo tiempo rechazaba las alternativas predominantes. Ello nos permite atribuir una contradicción ideológica, ya que se planteaba la necesidad de reactivar la economía desde una matriz heterodoxa, pero sin tocar el tipo de cambio fijo:

La búsqueda de una salida a la crisis debe contemplar la formulación de un programa de reversión del estancamiento y la pérdida de inversiones productivas, de rescate de las economías regionales, de creación de demanda interna y puestos de trabajo. De otro modo, ningún programa fiscal, monetario o cambiario, tendrá sustento económico ni político (Editorial de Clarin, 09/12/2001).

En el marco de esta argumentación ambivalente, Clarín cuestionaba al modelo económico, al mismo tiempo que apoyaba el objetivo del equilibrio "fiscal, monetario y cambiario". De lo que se trataba era de "buscar consensos que contribuyan a minimizar los daños y a vehiculizar una salvación colectiva" (Editorial de Clarín, 09/12/2001). El empleo de la metáfora del paciente (Argentina) "dañado" implicaba cuestionar los efectos regresivos del modelo y reclamar políticas alternativas con el objeto de "salvarlo", a través de soluciones "consensuadas". Sin embargo, suponía también "curar" al paciente preservando la estabilidad monetaria y fiscal en torno al 1 a $1 \mathrm{y}$, por lo tanto, sin devaluar.

En comparación, los periodistas de Página 12 asumían una crítica más radicalizada y profunda al modelo de acumulación. Eduardo Aliverti, por ejemplo, planteaba una disyuntiva entre dos opciones igualmente favorables a la "clase dominante" y los "sectores de privilegio". Por un lado, un proyecto dolarizador, que favorecía a los bancos y las empresas privatizadas. Por el otro, un proyecto devaluador, que beneficiaba a la "burguesía neoindustrialista":

El escenario dantesco que plantean los intelectuales y economistas del establishment sólo representa la angustia provocada porque alguna tribu de la clase dominante saldrá herida de esta circunstancia. Según haya dolarización, o devaluación, o ambas cosas u otras, ganarán o perderán más o menos los bancos, o las privatizadas o la burguesía neoindustrialista local (...). Esta es una guerra de sectores de privilegio, y nunca una guerra del conjunto popular contra esos mismos sectores (Eduardo Aliverti,“¿Cuál es la pregunta?”, nota en Página 12, 12/12/2001, p. 9).

Otros periodistas de Página 12 replicaban los "rumores de devaluación y dolarización” (José Natanson, “Todos mirando lo que hace Cavallo", nota en Página 12,06/12/2001). E imaginaban "escenarios ominosos, más graves aún que el negro presente", frente a lo que se presentaba como un "derrumbe inevitable" (Mario Wainfeld, "Cuando todos parecen ir a la puerta 12", nota en Página 12, 03/12/2001). En el marco de estas metáforas que denotaban un fuerte pesimismo sobre el futuro ("colapso", "escenarios ominosos", "derrumbe inevitable”), en contraste con el optimismo de los discursos oficiales, ningún periodista descartaba la posibilidad de una devaluación o una dolarización. Algunos, incluso, sostenían que el Gobierno podía llegar 
a “aplicar las tres D”, es decir, "desdolarizar, devaluar y volver a dolarizar" los depósitos, para luego "liberarlos" y, de este modo, licuar los ahorros de los depositantes:

Con depósitos inmovilizados, el gobierno podría aplicar las `tres D’: desdolarizar, devaluar y volver a dolarizar, para entonces sí liberarlos. En ese caso, quienes quedaron atrapados en los bancos sufrirían una licuación de sus ahorros (Maximiliano Montenegro, "Preguntas que no se hacen en Suiza", nota en Página 12, 02/12/2001).

Estos referentes mediáticos se hacían eco de los rumores circulantes, describían una realidad "negra" y, en ocasiones, proyectaban un futuro de derrumbe del Plan de Convertibilidad, que percibían como prácticamente inevitable. Sin embargo, no reclamaban explícitamente una salida de la paridad cambiaria. De esta manera, pese a sus críticas radicales, sus elucubraciones y diagnósticos, no prescribían una alternativa devaluacionista ni dolarizadora frente a la crisis terminal del modelo. Tampoco apoyaban un eventual default.

\section{LOS DISCURSOS PRO-DEVALUACIONISTAS Y LA IMPOSIBILIDAD DE ARTICULAR Y VIABILIZAR UN PROGRAMA ALTERNATIVO}

Junto con los referentes críticos de la Convertibilidad que rechazaban explícita o tácitamente la alternativa devaluadora, y aquellos que pretendían construir un modelo de país alternativo más allá de la disputa entre devaluadores y dolarizadores, en esta última fase algunos actores políticos minoritarios apoyaban explícitamente una salida devaluacionista. Uno de los pocos referentes políticos que se animaba a respaldar en público la opción de la devaluación era el economista ortodoxo José Luis Espert. Durante los años noventa este economista de la fundación neoliberal CEMA apoyó la estabilidad monetaria del 1 a 1 y enfocó las críticas en los "excesos" del gasto público (José Luis Espert, La Nación, "Económico", 07-04-93, p. 1). En la fase de crisis terminal del modelo, junto con un fuerte cuestionamiento al "congelamiento de los ahorros” del Corralito, Espert adhería, en cierto modo, a una devaluación de la moneda:

Esta limitación a las extracciones es un congelamiento de los ahorros y el comienzo de una profundización de la crisis financiera y económica de características monumentales. La poca gente que pueda ahorrar va a comprar dólares y los va a mandar afuera. Con tal de no devaluar, se hace cualquier barrabasada en materia económica (José Luis Espert, CEMA, Página 12, 02/12/2001).

Sin embargo, como se puede apreciar a partir del empleo del giro "con tal de no devaluar" (que no es equivalente a expresar que "hay que devaluar"), la demanda devaluacionista sólo se hacía presente de un modo indirecto. ${ }^{22}$ Además, Espert no pretendía devaluar la moneda para construir un modelo de país alternativo al financiero-neoliberal. En cambio, su propuesta se inscribía dentro del mismo proyecto neoliberal de readecuación de la dolarización del menemismo y el resto de los economistas del CEMA. Este proyecto consistía en realizar una fluctuación del tipo de cambio, para luego profundizar el mismo programa de ajuste ortodoxo e inserción imperialista y colonial al ALCA. ${ }^{23}$

Quien sí asumía una posición prodevaluacionista era Armando Cavalieri. El 5 de diciembre el titular del gremio de Empleados de Comercio se reunió en la Casa Rosada (acompañado por los sindicalistas Daer y West Ocampo) con el Jefe de Gabinete Chrystian Colombo. El gremialista de la CGT le pidió a Colombo que el Gobierno implementara una "devaluación moderada" para "mejorar el tipo de cambio" y promover las exportaciones, antes que fuera una decisión impuesta por los agentes económicos. En palabras de Cavalieri: "Es mejor que acordemos todos un dólar para exportar y que no sea una devaluación impuesta por el mercado" (Armando Cavalieri, Clarín, 06/12/2001).

A diferencia de Espert, un economista neoliberal del CEMA afín al proyecto dolarizador del menemismo, Cavallieri asumía de un modo más explícito la necesidad de salir del esquema de Convertibilidad. Además, pretendía acordar una devaluación para fomentar la exportación productiva, por lo que convergía con las posiciones heterodoxas de flotación cambiaria. En ese marco, el sindicalista de la CGT procuraba establecer 
una especie de acuerdo colectivo para evitar una devaluación provocada por el accionar de los agentes económicos más poderosos. Sin embargo, el reclamo devaluacionista sería rechazado categóricamente por Colombo, quien le respondió al instante: "Vos tenés la idea fija, cambiá el libreto por favor" (Chrystian Colombo, Clarín, 06/12/2001). En los días siguientes Cavalieri profundizó las críticas al modelo económico, el rechazo a la Convertibilidad y el reclamo para que el gobierno de De la Rúa realizara una "devaluación moderada" (Armando Cavallieri, Clarín, 11/12/2001, p. 19). Obtuvo, además, el apoyo del gremialista Andrés Rodríguez, quien sostuvo que "El 1 a 1 es una herramienta y no un dogma" (Andrés Rodríguez, Clarín, 11/12/2001, p. 19). Sin embargo, este reclamo fue ignorado por el Gobierno, que se opuso de forma tajante a devaluar la moneda y salir de la Convertibilidad. Más allá de este rechazo gubernamental, las posiciones pro-devaluacionistas, entre las que se destacaban los proyectos de devaluación encubierta de los economistas del Grupo Fénix, contaban con una serie de limitaciones políticas más amplias para viabilizarse:

1. Partían desde concepciones político-ideológicas opuestas entre sí (heterodoxas-neo-keynesianas/ neoestructuralistas vs. ortodoxas-neoliberales).

2. No explicitaban un indicador porcentual concreto de devaluación (es decir, en qué porcentaje devaluar la moneda), ni tampoco el tipo de flotación de la moneda conveniente (sucia o administrada). De este modo, los reclamos pro-devaluacionistas asumían una forma vaga, difusa e imprecisa.

3. Las diferentes posiciones heterodoxas no acordaban entre sí sobre las políticas económicas y sociales a tomar una vez devaluada la moneda (meras compensaciones particulares, o bien llevar a cabo un proyecto anti-neoliberal). En ese marco, no lograban converger políticamente en la estructuración coherente de un programa alternativo al Régimen de Convertibilidad que criticaban.

4. No contaban con el apoyo del jefe de Estado, los ministros de Gobierno, ni tampoco de los dirigentes de las principales fuerzas político-partidarias, para canalizar institucionalmente sus demandas devaluacionistas.

5. No contaban con el apoyo político de los titulares de las corporaciones empresariales del Grupo Productivo, y eran rechazadas por las empresas privatizadas, economistas ortodoxos, banqueros, operadores financieros y otros referentes del establishment internacional, las principales centrales sindicales y los más importantes grupos mediáticos locales.

6. Las posturas devaluacionistas eran rechazadas, en general, por una enorme porción de la ciudadanía, que mantenía un consenso básico sobre la continuidad del 1 a 1 .

7. En el marco de los puntos anteriores, constituían reclamos aislados, desarticulados y desorganizados a nivel político-institucional y social para poder consensuar, articular y viabilizar un programa alternativo al modelo de Convertibilidad.

\section{Conclusiones}

Durante la crisis de diciembre de 2001 se asistía a una intensa disputa de sentidos en la escena pública en torno a los fundamentos de la hegemonía neoliberal. Por un lado, encontramos en esta fase un paquete de discursos ortodoxo-neoliberal que se estructuraba en defensa de la paridad cambiaria y las políticas económicas de ajuste fiscal del Gobierno. Los principales exponentes de este macrodiscurso articulaban de una forma extensiva la defensa de la estabilidad en torno a la Convertibilidad con la preservación del sistema financiero y los ahorros de la gente. Algunos actores políticos que formaban parte de esta formación neoliberal, entre los que se hallaban economistas de las fundaciones ortodoxas, operadores financieros, banqueros, acreedores externos y otros referentes del establishment internacional, reclamaban profundizar el ajuste fiscalista para mantener la Convertibilidad. En otros casos, como en los editoriales de La Nación, el apoyo al Régimen de 
Convertibilidad se articulaba con la búsqueda de acuerdos de gobernabilidad entre las principales fuerzas políticas y sociales y el resguardo de la estabilidad institucional. Todos estos actores de poder convergían en la necesidad de preservar el modelo de Convertibilidad y rechazaban de un modo explícito o implícito una salida devaluatoria.

Por otro lado, encontramos un paquete de discursos de matriz heterodoxa y productivista nacional que se estructuraba en defensa de la producción nacional y el trabajo y cuestionaba las políticas económicas del modelo financiero-neoliberal. En esta formación productivista-nacional convergían una multiplicidad heterogénea de actores políticos de las fuerzas partidarias, mediáticas, económicas, sindicales y empresariales. Estos actores de poder criticaban, con diferentes énfasis, intensidades y grados relativos de profundidad, la paridad cambiaria fija, los efectos económicos y sociales regresivos de las reformas y ajustes estructurales y las interpelaciones oficiales. En algunos casos, como en los discursos de los economistas heterodoxos del Grupo Fénix, dirigentes de la CTA y la CGT disidente y periodistas de Página 12, reclamaban la construcción de un programa alternativo al modelo financiero-colonial y de ajuste neoliberal. En otros casos, como en los exponentes del Grupo Productivo (liderados por el titular de la UIA), demandaban modificaciones puntuales en el patrón de acumulación y asumían una modulación menos combativa. Sin embargo, encontramos que en esta fase los principales actores de poder de esta formación que conformaban el Grupo Productivo, el Movimiento Productivo Argentino y el Núcleo Nacional, mantenían un apoyo tácito a la estabilidad y no se pronunciaban abiertamente a favor de la devaluación monetaria (ni tampoco mencionaban el tema de la pesificación, que luego apoyarían en gran medida).

En condiciones de restricción de los préstamos financieros del FMI, fuga masiva de capitales y sangría de reservas monetarias, necesarias para conservar el esquema de caja de conversión de la Convertibilidad, encontramos que, en esta etapa de crisis terminal del modelo, el proyecto de dolarización se expresaba en la disputa hegemónica mediante una variante ortodoxa más realista. Esta propuesta financiera-neoliberal encabezada por Menem, Roque Fernández y sus economistas aliados del CEMA- pretendía realizar una fluctuación ponderada del tipo de cambio, para luego dolarizar toda la economía, profundizar las políticas de ajuste fiscal y flexibilización laboral y adherir al proyecto estadounidense del ALCA. Sin embargo, el proyecto político de readecuación de la dolarización, como intento de extremar y perpetuar el esquema convertible, acentuar la concentración económica, la explotación de la mano de obra asalariada y la subordinación al capital financiero internacional, era impugnado por el conjunto de los referentes heterodoxos de la formación productivista nacional. Además, si bien la opción dolarizadora no era descartada por Cavallo como último recurso para preservar la Convertibilidad, era rechazada por el presidente, quien mantenía una disputa de poder con Menem.

$\mathrm{Al}$ analizar las disputas hegemónicas en torno a la devaluación encontramos que en esta fase de crisis orgánica, con la excepción de unas pocas voces aisladas, los actores políticos predominantes rechazaban explícita o implícitamente dicha propuesta, que simbolizaba la pura anti-comunidad. El rechazo a la salida devaluatoria incluía tanto al presidente y a los principales referentes gubernamentales, como a los dirigentes empresariales y sindicales del Núcleo Nacional, economistas, banqueros y operadores financieros, periodistas y editorialistas de los principales medios de comunicación y exponentes heterodoxos de la UCR y el PJ no menemista. También encontramos que en esta fase un conjunto de actores de poder, entre los que se destacaban economistas y periodistas de Clarín, enunciaban públicamente los significantes devaluación y dolarización, a lo que se sumaba, en ocasiones, el peligro del default. Sin embargo, estosactores políticos no apoyaban explícitamente ninguno de estos proyectos en danza. En cambio, se limitaban a constatar y a describir la situación de crisis y se hacían eco de los rumores circulantes. En ocasiones, proyectaban, a través de metáforas que expresaban grados diferenciales de pesimismo sobre el futuro, una posible salida devaluacionista, dolarizadora y/o de cesación de pagos de la deuda. Pero sin respaldar ninguna de estas alternativas. 
Finalmente, encontramos que en esta última fasese presentaba mediáticamente un proyecto heterodoxo radicalizado que pretendía construir un modelo antagónico al Régimen de Convertibilidad. En esta propuesta radicalizada confluían los economistas heterodoxos del Grupo Fénix con referentes de la CTA y la CGT disidente, a lo que se sumaban periodistas de Página 12. A diferencia del proyecto productivistaexportador de los exponentes empresariales del Núcleo Nacional, que consistía en consensuar cambios parciales y limitados en el modelo de acumulación para mejorar la competitividad sectorial, el proyecto heterodoxo radicalizado pretendía construir un modelo de desarrollo globalmente alternativo al Plan de Convertibilidad, ajuste y explotación social de los trabajadores. Este proyecto alternativo al orden neoliberal consistía en llevar a cabo una "flexibilización" del tipo de cambio con desdolarización y flotación cambiaria, junto con una reprogramación de la deuda externa y una alianza estratégica con los países del Mercosur. De este modo, procuraba salir del esquema convertible y enterrar el proyecto financiero-neoliberal y de inserción imperialista al ALCA. Pero además, a diferencia de la propuesta moderada de la UIA, el proyecto de la CTA y los economistas del Grupo Fénix se articulaba con una estrategia para incrementar los salarios de los trabajadores y la inversión pública, a partir de un rol más activo del Estado. A través de dichas medidas, estos referentes heterodoxos radicalizados pretendían no sólo mejorar la competitividad económica para promover el desarrollo de la producción nacional de bienes transablescon alto valor agregado, sino también redistribuir el ingreso en favor de la clase trabajadora y proteger a las pymes ligadas al mercado interno.

Sin embargo, al igual que las propuestas neoliberales para extremar la Convertibilidad, radicalizar el ajuste fiscal recesivo y la subordinación al capital financiero internacional mediante una dolarización total del sistema, que eran rechazadas por las posiciones "anti-dolarizadoras", los proyectos heterodoxos más radicalizados para salir del Régimen de Convertibilidad y ajuste neoliberal no lograban establecer consensos básicos sobre el porcentaje en que debía devaluarse la moneda. Tampoco acordaban sobre el tipo de flexibilización cambiaria más conveniente (con flotación libre o administrada). Algunos referentes de poder de la CRA, incluso, consideraban políticamente inviable la flotación del tipo de cambio que proponían los economistas de Grupo Fénix. Pero, sobre todo, las propuestas de la modulación heterodoxa más radicalizada, entre las que se incluía el reclamo del dirigente de la CGT Cavalieri para realizar una devaluación moderada del tipo de cambio, constituían posiciones políticas minoritarias y aisladas, que eran vetadas por los principales actores de poder con posturas "anti-devaluacionistas". Además, eran rechazadas por los referentes ortodoxos continuistas del orden financiero-neoliberal. En esas circunstancias, durante la crisis terminal de diciembre de 2001, las posiciones más críticas del modelo de Convertibilidad no lograban articularse entre sí en la disputa hegemónica. Tampoco lograban converger con las principales fuerzas político-institucionales y sociales para consensuar y hacer viable una efectiva salida devaluatoria del modelo. En otras palabras, los posicionamientos más intensamente críticos del programa capitalistaneoliberal asentado en la Convertibilidad no contaban en la lucha de poder con los consensos necesarios ni la fuerza performativa para organizar política y socialmente un modelo de desarrollo alternativo.

Si tenemos en cuenta que, desde la teoría de la hegemonía, la articulación equivalencial de demandas sociales y su universalización retórico-política resulta una precondición del éxito hegemónico, en esta última fase del modelo se presentaba, en cambio, una imposibilidad de trascender el particularismo de las demandas y una fuerte dispersión y desarticulación hegemónica, incluso dentro del propio campo heterodoxo. Estas condiciones de intenso antagonismo entre los referentes políticos de ambos paquetes de discursos, y de fragmentación ideológica interna dentro del campo heterodoxo en dos modulaciones con diversos grados de radicalidad, se expresaban en la disputa por la hegemonía a través de un juego de vetos políticos mutuos entre los principales actores de poder. Ello obturaba la posibilidad de articular las diferentes demandas particulares de un modo más universalista y viabilizar políticamente un programa alternativo al sistema de Convertibilidad, endeudamiento estructural, ajuste recesivo, desindustrialización, precarización laboral y exclusión social de las mayorías populares. 


\section{Bibliografía}

Abeles, M. (1999). El proceso de privatizaciones en la Argentina de los noventa: ‘reforma estructural o consolidación hegemónica? Época. Revista Argentina de Economía Politica, 1(1), 95-114

Amadeo, J. (2011). Ideas económicas y poder político: las reformas estructurales en la agenda política argentina. En M. A. Rossi y A. López (comps.), Crisis y metamorfosis del Estado argentino. El paradigma neoliberal en los noventa (pp. 99-126). Bs. As.: Luxemburg

Arceo, E. (2002). ALCA: Neoliberalismo y nuevo pacto colonial. Bs. As.: CTA

Aronskind, R. (2007). Riesgo pais. La jerga financiera como mecanismo de poder. Bs.As.:Capital intelectual

Aronskind, R. (2008). Controversias y debates en el pensamiento económico argentino. Bs. As.: UNGS-Biblioteca Nacional

Aruguete, N. (2015). El poder de la agenda: política, medios y público. Bs. As.: Biblos

Basualdo, E. (2000). Concentración y Centralización del capital en la Argentina durante la década de los noventa. Bs. As.: Universidad Nacional de Quilmes

Basualdo, E. (2001). Sistema político y modelo de acumulación en la Argentina. Bs. As.: FLACSO-Universidad Nacional de Quilmes

Basualdo, E. (2006). Estudios de historia económica argentina: desde mediados del siglo XX a la actualidad. Bs. As.: Siglo XXI-FLACSO

Beltrán, G. (2006). Acción empresaria e ideología. La génesis de las reformas estructurales. En A. Pucciarelli (coord.), Los años de Alfonsin (pp. 199-243). Bs. As.: Siglo XXI

Beltrán, G. (2011). Las paradojas de la acción empresaria. Las asociaciones del empresariado argentino y la persistencia de las reformas estructurales. En A. Pucciarelli (coord.), Los años de Menem: La construcción del orden neoliberal (pp. 221-261). Bs. As.: Siglo XXI

Bonvecchi, A. (2002). Estrategia de supervivencia y táctica de disuasión. Los procesos políticos de la política económica después de las reformas estructurales. En M. Novaro (comp.), El derrumbe politico en el ocaso de la convertibilidad (pp. 107-193). Bs. As.: Norma.

Califano, B. (2012). El momento fundamental para sufrir privatización: políticas de comunicación en la Argentina neoliberal. Global Media Journal, 9, 52-71

Cantamutto, F. y López, E. (2013). Las demandas económicas de la clase trabajadora en el nuevo modo de desarrollo argentino (2002-2011). Conflicto Social, 6,(10). Recuperado de: http://www.webiigg.sociales.uba.ar/conflictos ocial/revista/10/06_Lopez_Cantamutto.pdf

Cantamutto, F. y Wainer, A. (2013). Economia Politica de la Convertibilidad. Disputa de intereses y cambio de régimen. Bs. As.: Capital intelectual

Castellani, A. y Schorr, M. (2004). Argentina: Convertibilidad, crisis de acumulación y disputas en el interior del bloque de poder económico. Cuadernos del Cendes, 57, 55-81

Castellani, A. y Szkolnik, M. (2011). Devaluacionistas y dolarizadores. La construcción social de las alternativas propuestas por los sectores dominante ante la crisis de la Convertibilidad. Argentina 1999-2001. Papeles de Trabajo, 18. Recuperado de: http://www.unsam.edu.ar/institutos/idaes/docs/DocIS_18_Castellani_Szkolnik .pdf

Cheresky, I. (2003). Las elecciones nacionales de 1999 y 2001. En I. Cheresky y J. M. Blanquer (comps.), De la ilusión reformista al descontento ciudadano. Las elecciones en Argentina, 1999-2001 (pp. 19-51). Rosario: Homo sapiens

De Lourenco, A. (2001). América Latina como dominio: el fracaso de una nueva utopía. Época. Revista Argentina de Economía Politica, 3(3), 63-96

Fair, H. (diciembre, 2007). El Plan de Convertibilidad y la articulación de la hegemonía menemista. Un estudio de caso de la primera presidencia de Menem (1989-1995). Ponencia presentada en las I Jornadas de Economía Política, Los Polvorines, 6 y 7 de diciembre. Recuperado de https://www.ungs.edu.ar/cm/uploaded_files/file/ ecopol/Fair_Hernan.pdf 
Fair, H. (2013). El desvanecimiento del discurso nacional popular en la Argentina. Entramado, 9(2), 118-137

Fair, H. (2014a). Los debates en torno al núcleo central de la hegemonía neoliberal en la Argentina. Los casos de la Convertibilidad y la devaluación. Politica y Sociedad, 51(3), 727-755

Fair, H. (2014b). El (no) debate político e ideológico en torno al núcleo nodal de la hegemonía neoliberal en la Argentina. El caso del significante estabilidad durante la etapa de sedimentación de la hegemonía menemista. PostData, 19, 583-635

Fair, H. (2016). La construcción y articulación de la hegemonía menemista frente al campo empresarial y el establishment internacional en los años 90. Espiral: Estudios sobre Estado \& Sociedad, 23, 79-118

Fair, H. (2017). Crisis del modelo de Convertibilidad y reformas neoliberales en la Argentina. Aposta, 73, 221-280. Recuperado de http://www.apostadigital.com/revistav3/hemeroteca/herfair1.pdf

García Delgado, D. (2003). Estado-nación y la crisis del modelo. Bs. As.: Norma.

Gramsci, A. (2008). Notas sobre Maquiavelo, sobre la politica y sobre el Estado moderno. Bs. As.: Nueva visión

Heredia, M. (2011). La hechura de la política económica. Los economistas, la Convertibilidad y el modelo neoliberal. En A. Pucciarelli (coord.), Los años de Menem. La construcción del orden neoliberal (pp. 179-220). Bs. As.: Siglo XXI

Heredia, M. (2014). 'No se puede pensar la muerte'. Los economistas y sus dilemas ante la crisis de la convertibilidad. En A. Pucciarelli y A. Castellani (coords.), Los años de la Alianza: La crisis del orden neoliberal (pp. 247-294). Bs. As.: Siglo XXI

Howarth, D. (2000). Discourse. Concepts in the social sciences. Buckingham: Open University Press

Kan, J. (2009). Vuelta previa al 2001. La devaluación del Real de 1999 y algunas implicancias en la burguesía argentina. En A. Bonnet y A. Piva (comps.), Argentina en pedazos. Luchas sociales y conflictos interburgueses en la crisis de la Convertibilidad (pp. 223-251). Bs. As.: Continente-Peña Lillo

Laclau, E. (1985). Tesis acerca de la forma hegemónica de la política. En J. Labastida (coord.), Hegemonia y alternativas politicas en América Latina (pp. 19-44). UNAM: México.

Laclau, E. (1993). Nuevas reflexiones sobre la revolución de nuestro tiempo. Bs. As.: Nueva visión

Laclau, E. (1996). ¿Por qué los significantes vacíos son importantes para la política? En Emancipación y diferencia (pp. 69-86). Bs. As.: Ariel

Laclau, E. (2005). La razón populista. Bs. As.: FCE

Laclau, E. (2014). Los fundamentos retóricos de la sociedad. Bs. As.: FCE

Laguado Duca, A. (2011). La construcción de la cuestión social. El desarrollismo postperonista. Bs. As.: Espacio

Mastrini, G. y Becerra, M. (2006). Periodistas y magnates. Bs. As.: Prometeo

Merino, G. (2015). Luchas por la conducción del Estado en Argentina entre 1999 y 2003. El Grupo Productivo yel cambio del modelo. Bs. As.: Edunam

Merino, G. (2016). Empresarios y política: constitución del Grupo Productivo en la Argentina y surgimiento de un nuevo actor político empresarial. Realidad Económica, 302, 35-63.

Morresi, S. (2007). ¿Más allá del neoliberalismo? Estado y neoliberalismo en los años noventa. En E. Rinesi, G. Nardacchione y G. Vommaro (edits.), Los lentes de Victor Hugo. Transformaciones politicas y desafios teóricos en la Argentina reciente (pp. 117-150). Bs. As.: Prometeo-UNGS

Morresi, S. (2008). La nueva derecha argentina: La democracia sin politica. Bs. As.: Biblioteca Nacional-UNGS

Morresi, S. (2011). Las raíces del neoliberalismo argentino (1930-1985). En M. A. Rossi y A. López (comps.), Crisisy metamorfosis del Estado argentino. El paradigma neoliberal en los noventa (pp. 47-69). Bs. As.: Luxemburg

Nemiña, P. (2014). De la esperanza a la caída. En A. Pucciarelli y A. Castellani (coords.), Los años de la Alianza (pp. 215-246). Bs. As.: Siglo XXI

Novaro, M. (2006). La crisis de la Convertibilidad. En M. Novaro, Historia de la Argentina Contemporánea (pp. 265-290). Bs. As.: Edhasa

Peralta Ramos, M. (2007). La economía política argentina: poder y clases sociales (1930-2006). Bs. As.: FCE 
Pousadela, I. (2003). La oposición progresista frente al consenso neoliberal. Ensayo acerca de la relación entre Política y Economía en la Argentina de los años '90. En I. Cheresky y J. M. Blanquer (comps.), De la ilusión reformista al descontento ciudadano. Las elecciones en Argentina, 1999-2001 (pp. 117-155). Rosario: Homo sapiens

Salvia, S. (2014). ¿Devaluación sin devaluadores? Ciclos de la historia, la economía y la sociedad, 22(43)

Schorr, M. (2001). ¿Atrapados sin salida?: la crisis de la Convertibilidad y las contradicciones en el bloque de poder económico. Bs. As.: Documento de Trabajo de FLACSO. Recuperado de http://bibliotecavirtual.clacso.org.ar /Argentina/flacso-ar/20121206090957/schorr.pdf

Schorr, M. y Wainer, A. (2005). Argentina: ¿muerte y resurrección? Notas sobre la relación entre economía y política en la transición del modelo de los noventa al del dólar alto. Realidad Económica, 211, 32-65

Thwaites Rey, M. (1999). Ajuste estructural y reforma del Estado en la Argentina de los `90. Realidad económica, 160, 76-109

Thwaites Rey, M. (2003). La (des)ilusión privatista: El experimento neoliberal en la Argentina. Bs. As: EUDEBA

\section{OTRAS FUENTES}

Diarios Clarin, La Nación y Página 12 (ediciones electrónica e impresa)

INDEC (1998). Anuario Estadístico de la República Argentina, Vol. 14

Discursos oficiales del Presidente de la Nación, Dr. Carlos Saúl Menem, Dirección General de Difusión, Secretaría de Medios de Comunicación, Presidencia de la Nación, República Argentina, año 1991

\section{Notas}

1 En una primera instancia se analizaron los discursos desde la versión digital de los diarios. Luego, se corroboraron los datos extraídos a través de una revisión de la versión impresa de estos mismos medios de prensa escrita.

2 Mientras que Página 12 representa un diario con ideas de centroizquierda, La Nación, como "Tribuna de doctrina”, históricamente promovió las ideas liberal-conservadoras de las elites dominantes (Laguado Duca, 2011, p. 44). En el caso de Clarín, el matutino forma parte de un grupo económico-mediático, de tendencia desarrollista, que creció significativamente en los años noventa al compás de las políticas de privatización y re-regulación a favor del capital concentrado del menemismo (Califano, 2012). A comienzos del 2000, el Grupo Clarín ya ejercía un control altamente concentrado de las fuentes de información (Mastrini y Becerra, 2006).

3 Para la caracterización de los conceptos de ortodoxia y heterodoxia nos basamos en los usos de los paradigmas dominantes del pensamiento económico argentino. Al respecto, véanse Aronskind (2008, pp. 40-46, pp. 84-85), Amadeo (2011, pp. 108 y 116) y Heredia (2011, pp. 210-211, 2014, pp. 250-254).

4 El periodista David Cufré sostenía que los técnicos del FMI habían encontrado una "brecha" en el Presupuesto previsto para el 2002 y los años subsiguientes. Para cerrar esa brecha, Kohler le habría pedido a Cavallo que realizara un ajuste fiscal de 4 mil millones de dólares ("Mingo tendió un puente y vino una aplanadora”, Página 12, 08/12/2001, p. 2).

5 Durante la campaña de 1995, mientras que Menem y Bordón respaldaban la estabilidad y la continuidad de la Convertibilidad, Massaccesi sostenía que la Convertibilidad era una "medida de emergencia" y que era necesario salir "gradualmente" de la misma. Aunque aclaraba que se haría sin devaluar la moneda, ya que "es por demás prematuro y peligroso hablar de una devaluación” ( Clarín, 11/01/95, 13/04/95 y 07/05/95; La Nación, 08/05/95, 09/05/95, 12/05/95 y 13/05/95).

6 Recordemos que, en caso de adoptar el proyecto de dolarización, la Argentina se hubiera visto forzada a tener (como mínimo) el mismo nivel de productividad que la economía estadounidense (en el 2001, con la excepción de unos pocos sectores, muy superior a la argentina) (Schorr, 2001, p. 12).

7 En 1991 el gobierno de Menem estableció la dolarización de las tarifas de servicios públicos privatizados. Al mismo tiempo, convalidó ajustes tarifarios periódicos de acuerdo a la evolución de los índices de precios de los Estados Unidos, que además crecieron por encima de sus similares en el ámbito local. Esta medida de "re-regulación” violaba la Ley de Convertibilidad, que prohibía indexar tarifas de servicios. Junto con otras irregularidades del proceso de privatizaciones de los 90 (incumplimiento de pautas previstas de inversión, entes reguladores creados ex post o carentes de efectiva autonomía), significó un notable incremento patrimonial de las prestatarias de los servicios públicos privatizados y convalidó la formación de monopolios y oligopolios no innovadores, no transitorios y con un escaso riesgo empresarial. Sobre este tema, véanse Abeles (1999) y Thwaites Rey (2003). 
8 Roque Fernández fue elegido ministro de Economía de Menem en 1996 en reemplazo de Cavallo. Durante su gestión mantuvo a la Convertibilidad en "piloto automático", sin introducir ajustes en el esquema cambiario-monetario (Heredia, 2011, p. 209).

9 El CEMA fue fundado en 1978 para difundir las ideas neoliberales. Varios de sus economistas se unieron al gobierno de Videla durante la Dictadura cívico-militar. Adscripto ideológicamente a la Escuela monetarista de Chicago de Milton Friedman, sus principales referentes intelectuales eran Pedro Pou, Carlos Rodríguez y Roque Fernández (Morresi, 2007, pp. 124-125, 2008, pp. 69-70, 2011, p. 59).

$10 \mathrm{Si}$ bien ambos términos fueron articulados retóricamente en los 90, se debe distinguir entre el concepto de Convertibilidad y el de tipo de cambio fijo. Como señala Aronskind, "Convertibilidad significa que en poder del Banco Central existe una cantidad de divisas equivalente al dinero circulante, dado un tipo de cambio determinado". En cambio, "tipo de cambio fijo implica que la cotización de la moneda extranjera está fijada -no fluctúa librementepor el Gobierno". Por lo tanto, puede existir un sistema de Convertibilidad con un tipo de cambio 2 a 1 o 4 a 1 . En este sentido, eventualmente, "El gobierno pudo haber devaluado la moneda, sin afectar por ello la regla básica de la Convertibilidad" (Aronskind, 2007, p. 74, nota 45).

11 Junto con una política de reforma financiera, apertura comercial y desregulación económica que se inició en junio de 1977, en diciembre de 1978 el Ministro de Economía Martínez de Hoz introdujo la “Tablita”. El nuevo esquema consistía en un sistema de incrementos de la tasa de cambio menores siempre a la tasa de inflación interna (Peralta Ramos, 2007, p. 173)

12 Durante las elecciones legislativas de 1991 triunfaron los candidatos que con mayor intensidad apoyaban la estabilidad. Además, ninguno de los principales candidatos planteó la necesidad de derogar el régimen cambiario o devaluar la moneda. Eduardo Duhalde, candidato triunfante del justicialismo por la Provincia de Buenos Aires por el Frente Justicialista de la Producción y la Estabilidad (FREJUPE), sostenía que "esta estabilidad se está afirmando cada día más y es la plataforma de nuestro proyecto de producción y trabajo" (La Nación, 31/08/91) (véase también el afiche de campaña publicado en Página 12,06/09/91, p. 5). De la Rúa, candidato de la UCR por Capital, proponía "combatir la corrupción, garantizar seguridad y justicia, defender la solidaridad social y el crecimiento económico, porque, sin ellas, la estabilidad que todos anhelamos, sería estéril" (La Nación y Página 12, 27/08/91, p. 11). Eduardo Angeloz, candidato por Córdoba, sostenía que "la estabilidad es un bien de todos" y "sólo los necios e incompetentes pueden atentar contra ella” (La Nación, 24/08/91). Del mismo modo se expresó el candidato oficialista por la Provincia de Buenos Aires, Carlos Ruckauf (Página 12, 04/09/91, p. 9). Además, tanto Ruckauf, como De la Rúa y Alsogaray, concluyeron su campaña defendiendo la estabilidad (Clarín, 07/09/91). En contraste, las posiciones más combativas de Ubaldini y el grupo de los ocho diputados "rebeldes" del justicialismo fueron duramente derrotados (INDEC, 1998, p. 258; Clarín, 09/09/91; Página 12, 29/10/91, p. 2).

13 Durante las elecciones legislativas del 3 de octubre de 1993, en las que el PJ triunfó en 17 provincias y en la propia Capital Federal (La Nación, 05/10/1993), los principales candidatos de la UCR, el PJ, el Frente Grande y Unidad Socialista, se debatieron centralmente sobre la corrupción y el intento de Menem de plebiscitar su gestión (Clarín y La Nación, 15/09/93 al 01/10/93). Al mismo tiempo, ninguno de ellos criticó la estabilidad, ni propuso a nivel programático devaluar la moneda. En el PJ, mientras Menem sostenía que "está en juego el modelo y candidatos que van a sostener el modelo" (Clarín, 30/09/93, p. 20) y apoyaba "la estabilidad y la Convertibilidad" (Clarín, 28/09/93, p. 5), el triunfante candidato a senador porteño Erman González avalaba toda la gestión de Menem de forma acrítica. Duhalde, además, reconocía que el cómodo triunfo del PJ con casi el $43 \%$ de los votos a nivel nacional tenía "mucho que ver con el plan económico de Cavallo” (Clarín, 10/10/93, p. 8). De la Rúa, candidato a senador por Capital, asumía un discurso moralista contra la "corrupción", la "corte adicta" y la falta de una "justicia independiente" (Clarín, 19/09/93, p. 12; La Nación, 01/10/93, p. 13). Pero, junto con el pedido de un "cambio moral y solidario” (Clarín, 29/09/93, p. 12), "más justicia y más honestidad" (Clarín, 01/10/93, p. 10) y un mayor "equilibrio de poder" (Clarín, 25/09/93, p. 5, 26/09/93, pp. 6 y 12, 29/09/93, p. 13), "Chupete” apoyaba la estabilidad. El mismo discurso moralista contra la corrupción y el "poder desmedido del Ejecutivo" se expresaba en la candidata a diputada de la UCR Marta Mercader (Clarín, 27/09/93, p. 14). Sin embargo, la escritora reclamaba "estabilidad con crecimiento, con trabajo y con salud" (Clarín, 01/10/93). Los propios De la Rúa y Mercader se expresaron juntos a favor de "recobrar la esperanza de un país que, a partir de la estabilidad, se desarrolle con honestidad y con justicia” (Clarin, 27/09/1993, p. 12). Storani criticaba las "privatizaciones mal concretadas" (La Nación, 01/10/93, p. 13) y, en una ocasión, cuestionó la "rigidez del Plan de Convertibilidad”. Pero al mismo tiempo rechazaba la devaluación, porque "tendría efectos negativos” (Clarín, 17/09/93, p. 6). Storani sostenía: "nosotros queremos defender la estabilidad, porque ha costado mucho y porque es importante como presupuesto para el desarrollo". Además, rechazaba la devaluación, “porque la Argentina está altamente endeudada en dólares” y porque "una devaluación produciría un impacto psicológico brutal que terminaría por generar inflación” (La Nación, 01/10/93, p. 14). El Comité Nacional de la UCR (Clarín, 16/09/93, p. 10), el Bloque de diputados de la UCR (La Nación, 01/10/93, p. 10) y "Chacho" Álvarez (Clarín, 19/09/93, p. 5), también expresaron un consenso básico sobre la "estabilidad". Y 
Terragno en esta etapa reclamaba un "modelo industrial exportador", un mayor "control” en las privatizaciones y una apertura comercial "gradual”. Aunque al mismo tiempo rechazaba la opción devaluadora (Clarin, 17/09/93, p. 12).

14 A modo ilustrativo, durante la campaña presidencial de 1995 el Consejo de la Producción, que nucleaba a las principales corporaciones empresariales con sindicalistas de la CGT, realizó un comunicado conjunto con la firma del titular de la UIA, el vicepresidente de ADEBA, el presidente de la CAC, el presidente de la CRA y los sindicalistas Cassia, Pedraza y Andrés Rodríguez, en el que se "rechaza vehementemente" cualquier "posibilidad de devaluación” (Clarín, 03/03/95). A su vez, el grupo de los 8 (corporaciones rurales, industriales y banqueros) expresó en un comunicado su firme respaldo al Plan de Convertibilidad, "evitando el recurso impensable de la devaluación" (Clarín, 08/03/95). El presidente de la UIA sostenía que "la devaluación no se nos pasa por la cabeza" (Clarín, 12/03/95), mientras que la CGT y las 62 Organizaciones expresaban su apoyo a la "moneda estable" y a la "estabilidad" (Clarin, 02/05/95, 10/05/95, 11/05/95; Clarín y La Nación, 12/05/95). El consenso básico sobre el núcleo medular y la no devaluación también se hacía presente, además de Menem, en el candidato del FREPASO José Bordón. Pese a las críticas al modelo económico, Bordón defendía a la estabilidad como un "compromiso ineludible" (Página 12, 07/05/95, p. 12 y 12/05/95). Además, sostenía que "Cavallo no debe devaluar" y dejaba en claro: "Yo no voy a devaluar si soy Presidente" (Clarín, 05/05/95). A tono con el discurso de Menem, Bordón afirmaba que "no vamos a devaluar" y sostenía que pensaba "hacer todos los esfuerzos para que no se siga debilitando la Convertibilidad" (Clarín, 07/04/95). Este compromiso implicaba "defender totalmente la paridad cambiaria y la estabilidad de la moneda" y reconocer que "una devaluación del peso sería una verdadera catástrofe” (Clarín, 10/05/95). Al respecto, véanse también Fair (2007) y Morresi (2008, pp. 92-93).

15 En este sentido, ya en 1993 el titular de la Federación Agraria, Humberto Volando, había criticado fuertemente a la Convertibilidad. Sin embargo, al mismo tiempo reconocía: “¡¿Cómo vamos a pedir devaluación, si el $85 \%$ de los productores (rurales) está endeudado en dólares?! Lo que queremos es deflación de nuestros costos” (Clarín, 22/06/93, p. 18).

16 Desde comienzos del 2001 se habían incorporado al Grupo Productivo nuevos integrantes de las fuerzas políticopartidarias, empresariales y sindicales. El 21 de junio estos sectores confluyeron en el Movimiento Productivo Argentino, bajo el liderazgo político de Eduardo Duhalde y con el apoyo de Alfonsín. Las ideas de este bloque "neodesarrollista" triunfaron en las elecciones legislativas de octubre de ese año con un discurso crítico del orden financiero-neoliberal, pero que sólo se refería a la devaluación de una forma "velada”. La articulación entre el Grupo Productivo y la CGT oficial se constituyó el 29 de noviembre del 2001 como Núcleo Nacional (Merino, 2015, p. 216 y ss.).

17 La sospecha sobre la debilidad del sistema se hacía presente también en una porción de los ahorristas. El día posterior a la implementación del Corralito, Clarín informaba que "la gente" se preguntaba si "va a haber feriado bancario", si "estarán por devaluar" y si "podremos recuperar nuestros depósitos" (Clarín, 02/12/2001). Con el correr de los días, algunos ahorristas comenzaron a expresar su temor a que el Gobierno decidiera confiscar los depósitos, desdolarizarlos y luego devaluar la moneda. Eduardo, un comerciante del barrio porteño de Caballito, señalaba resignado: "Van a pesificar, van a devaluar, y van a dolarizar otra vez. Y vas a cobrar el resto de tu guita en papelitos de colores" (Clarín, 09/12/2001). Los cambios en las percepciones se traducían, además, en las prácticas discursivas. En este sentido, en su edición del 7 de diciembre Clarín informaba que, frente a la creciente demanda de dólares, algunos bancos ya habían dejado de vender o limitaban la venta de esa divisa (Clarín, 07/12/2001, p. 32). Además, en las casas de cambio del microcentro porteño comenzaba a pagarse 1,40 pesos por cada dólar (Clarín, 08/12/2001), señal del cuestionamiento fáctico de la creencia fantasmática en el 1 a 1 .

18 Sobre las diferentes visiones dentro del FMI en torno a la Convertibilidad durante la crisis del 2001, véase Nemiña (2014, en particular p. 236).

19 Como señala De Lourenco (2001, p. 85), junto con el esquema de currency board y la alternativa de la dolarización explícita, existe un amplio espectro con "distintos grados de flexibilidad" en la capacidad del Banco Central para regular las tasas de interés y controlar los capitales. Entre ellos, el cambio fijo reajustable, bandas cambiarias (de diversos tamaños), cambio con fluctuación sucia, etc.

20 Malan, además, rechazaba la propuesta de dolarización con argumentos similares al Grupo Productivo. Consideraba que, a diferencia de "Ecuador y Panamá", "la economía de Argentina tiene un tamaño demasiado grande, por lo que su dolarización sería muy compleja” (Clarín y Página 12, 08/12/2001).

21 En este sentido, Heredia (2014, pp. 265-267 y ss.) destaca que entre 1998 y el 2001 los economistas heterodoxos (claramente minoritarios en cantidad) criticaban a la Convertibilidad, pero al mismo tiempo consideraban tabú la salida del 1 a 1.

22 Cabe destacar que este discurso no fue replicado en la edición electrónica correspondiente al diario Clarín y que La Nación sólo replicó un fragmento más corto del mismo.

23 La estrategia dolarizadora del menemismo-CEMA se articulaba con un proyecto político de más largo aliento para crear un área de libre comercio de las Américas (ALCA). Este proyecto aperturista-neoliberal se remontaba a la llamada Iniciativa de las Américas y fue incentivado por el gobierno de Clinton en Estados Unidos, ya que se beneficiaría fuertemente en sus intercambios comerciales y financieros (al respecto, véase Arceo, 2002). Ya desde 1991, este proyecto 
de subordinación colonial fue difundido por el menemismo, que lo presentaba como un "avance" inevitable del planeta "hacia el universalismo" (Discurso oficial de Menem del 19/09/91, p. 202). 